NBER WORKING PAPER SERIES

\title{
CENTRAL BANK DIGITAL CURRENCY: WHEN PRICE AND BANK STABILITY COLLIDE
}

\author{
Linda Schilling \\ Jesús Fernández-Villaverde \\ Harald Uhlig \\ Working Paper 28237 \\ http://www.nber.org/papers/w28237 \\ NATIONAL BUREAU OF ECONOMIC RESEARCH \\ 1050 Massachusetts Avenue \\ Cambridge, MA 02138 \\ December 2020
}

The contribution of Linda Schilling has been prepared under the Lamfalussy fellowship program sponsored by the ECB and was originally named "Central bank digital currency and the reorganization of the banking system." We thank Agnese Leonello and an anonymous ECB referee for very insightful comments. The views expressed in this paper are those of the authors and do not necessarily reflect the views of the ECB. The views expressed herein are those of the authors and do not necessarily reflect the views of the National Bureau of Economic Research.

NBER working papers are circulated for discussion and comment purposes. They have not been peer-reviewed or been subject to the review by the NBER Board of Directors that accompanies official NBER publications.

(C) 2020 by Linda Schilling, Jesús Fernández-Villaverde, and Harald Uhlig. All rights reserved. Short sections of text, not to exceed two paragraphs, may be quoted without explicit permission provided that full credit, including $\odot$ notice, is given to the source. 
Central Bank Digital Currency: When Price and Bank Stability Collide

Linda Schilling, Jesús Fernández-Villaverde, and Harald Uhlig

NBER Working Paper No. 28237

December 2020

JEL No. E58,G21

\section{ABSTRACT}

A central bank digital currency, or CBDC, may provide an attractive alternative to traditional demand deposits held in private banks. When offering CBDC accounts, the central bank needs to confront classic issues of banking: conducting maturity transformation while providing liquidity to private customers who suffer "spending" shocks. We analyze these issues in a nominal version of a Diamond and Dybvig (1983) model, with an additional and exogenous price stability objective for the central bank. While the central bank can always deliver on its nominal obligations, runs can nonetheless occur, manifesting themselves either as excessive real asset liquidation or as a failure to maintain price stability. We demonstrate an impossibility result that we call the CBDC trilemma: of the three goals of efficiency, financial stability (i.e., absence of runs), and price stability, the central bank can achieve at most two.

Linda Schilling

Ecole Polytechnique CREST

5 Avenue le Chatelier

Palaiseau, Fran 91120

France

and CEPR

lin.schilling@gmail.com

Jesús Fernández-Villaverde

Department of Economics

University of Pennsylvania

The Ronald O. Perelman Center

for Political Science and Economics

133 South 36th Street Suite 150

Philadelphia, PA 19104

and CEPR

and also NBER

jesusfv@econ.upenn.edu
Harald Uhlig

Dept. of Economics

University of Chicago

1126 E 59th Street

Chicago, IL 60637

and CEPR

and also NBER

huhlig@uchicago.edu 


\section{Introduction}

Many central banks and policymaking institutions, such as the Bank of Canada, the Bank of England, the Bank for International Settlements, the ECB, the IMF, the People's Bank of China, the Sveriges Riksbank, and the G30, are openly debating the introduction of a central bank digital currency, or CBDC (Barrdear and Kumhof, 2016; Bech and Garratt, 2017; Chapman et al., 2017; Lagarde, 2018; Ingves, 2018; Kahn et al., 2019; Davoodalhosseini et al., 2020; Auer and Böhme, 2020; Auer et al., 2020; Group of 30, 2020).

The introduction and adoption of CBDCs have the potential to be a watershed for the monetary and financial systems of advanced economies. Since at least the classic formulation of Bagehot (1873), central banks have viewed their primary tasks as maintaining stable prices and ensuring financial stability through their role as lenders of last resort. With a CBDC, two additional and significant aspects come into play. First, a CBDC may become an attractive alternative to traditional demand deposits in private banks for all households and firms. Second, and as a result, the central bank may be transformed into a financial intermediary that needs to confront classic issues of banking such as maturity transformation and the exposure to a demand for liquidity induced by "spending" shocks (runs) of its private customers. $^{1}$

In this paper, we seek to model the interplay of these new and traditional roles to evaluate the advantages and drawbacks of introducing a CBDC concerning the subsequent reorganization of the banking system and its consequences for monetary policy, allocations, and welfare. To do so, we build on the classical model by Diamond and Dybvig (1983), which emphasizes a bank's role in maturity transformation: banks pool resources and finance longterm projects with demand deposits that can be withdrawn at a short time horizon to meet liquidity shocks. By offering risk-sharing, banks enable allocations that are not attainable under autarky. Yet, the optimal amount of risk-sharing requires banks to be prone to runs. Can maturity transformation still occur at the socially optimal level with a CBDC? Can a central bank do better and, for instance, avoid runs? Do new trade-offs arise?

\footnotetext{
${ }^{1}$ While both deposit-making and lending to the public by a central bank can be accomplished without a CBDC (as has often happened in the past; see Fernández-Villaverde et al., 2020, for historical examples), the operational logistics without digital means are too cumbersome in a large, modern economy to represent a likely policy option. Also, from the perspective of our paper, it is mainly irrelevant whether the deposits and loans in the CBDC are run directly by the central bank or by financial institutions that implement the directives of the central bank.
} 
We depart from the original formulation of the Diamond and Dybvig model in a crucial aspect. While Diamond and Dybvig (1983) consider intermediation with private banks, a CBDC implies central bank intermediation. This difference is consequential because a central bank can control the price level. For example, a central bank can issue additional units of a CBDC to cover losses in its loan portfolio, implicitly diffusing the costs of the credit losses among all holders of the currency. To allow for this feedback mechanism between the loan portfolio and the price level, we modify the basic Diamond and Dybvig (1983) model by imposing the condition that all contracts are nominal. We assume that real goods can only be traded against money, implicitly setting a form of a cash-in-advance constraint in the tradition of Svensson (1985) and Lucas and Stokey (1987), but suited to the digital world. In fact, a cash-in-advance constraint is more relevant in a CBDC world because other means of payment, such as the transfer of private deposits, might have disappeared.

In our model, classic bank runs may still occur due to a rationing problem, when liquidating illiquid real assets at a given price level. But since the central bank controls the price level and contracts are nominal, it can avoid rationing if it prefers. By issuing more currency, the monetary authority can always deliver on its obligation. But a simple "quantity theory of money intuition" implies that avoiding excess liquidation of real assets by issuing more currency implies sacrificing inflation targeting. Thus, our model illustrates how runs on a central bank can manifest themselves in two ways: either as a classic run, caused by the rationing of real assets, or as a run on the price level.

This dual nature of bank runs is part of a more general phenomenon. Imagine that the central bank has three goals: efficiency, financial stability (i.e., absence of runs), and price stability. We demonstrate an impossibility result that we call the CBDC trilemma: of its three goals, the central bank can achieve at most two; see Figure 1. As the first part of the trilemma, we prove that the central bank can always implement the socially optimal allocation in dominant strategies while deterring runs by credibly threatening high inflation whenever nominal spending is excessive. This threat is implemented by limiting the real asset liquidation in the case of a run, thereby rendering spending by patient agents suboptimal ex-post. Since depositors are rational, the central bank's inflation threat deters runs ex-ante such that high inflation only occurs off the equilibrium path. This result contrasts with the Diamond and Dybvig model, where banks do not have the option of changing the aggregate price level in response to a run. Therefore, there, runs can occur as equilibrium phenomena, 
in which case the social optimum does not obtain.

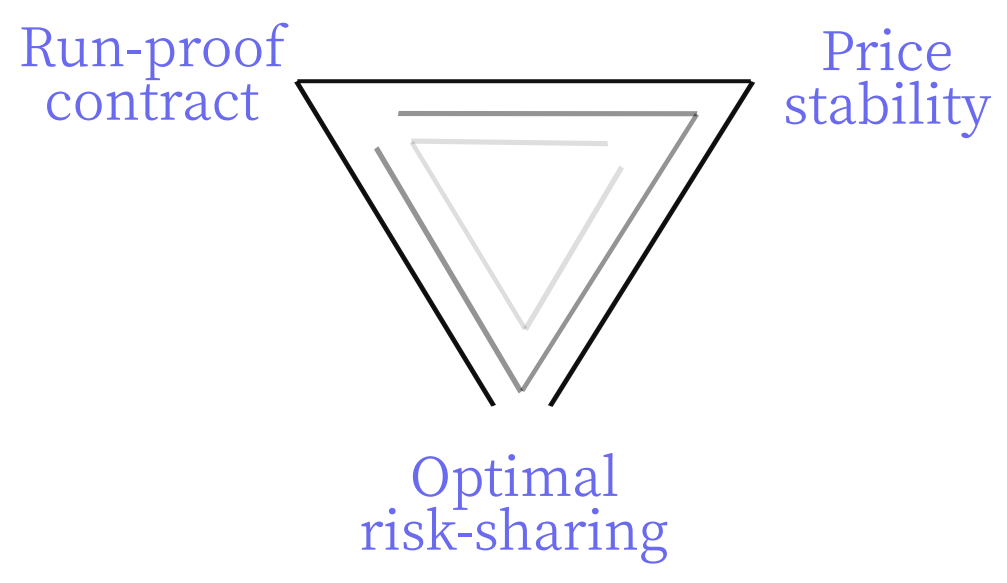

Figure 1: CBDC Trilemma: For the central bank, it is impossible to attain all three objectives at a time. When prioritizing one objective, at least one other objective has to be sacrificed.

On the second part of the trilemma, the threat of inflation may not be credible for modern central banks given their commitment to price stability, which is often reinforced in their governing charters or imposed by the political process. Would a central bank challenge its commitment to price stability should a run occur? When taking the central bank's commitment to price stability seriously, and enforcing it as the primary objective in all subgames, we find ourselves in the classic Diamond-Dybvig dilemma: either the allocation is suboptimal or classic bank runs can no longer be ruled out.

For the purpose of simplicity, our benchmark model is extreme in that there are no private banks: the central bank operates all real technology and provides all of the economy's deposit functionality. In an extension, we analyze how our results extend to the case where the central bank shares the deposit market with private banks. We show that, if the central bank and private banks coordinate their real asset liquidations, then runs can be deterred as before. If coordination is not possible, potentially due to the regulation of private banks, then the central bank can deter runs as long as it controls a sufficiently large share of the deposit market.

To address the concern that the central bank "takes over" the production side of the economy, one can suitably enrich the model as in Skeie (2008) or Allen et al. (2014), where the "real" side is arising from the interplay between workers and entrepreneurs (and their consumers), leaving the nominal side to the banking system and the central bank. The co- 
existence of a central bank and private banks and the consequential competition for deposits raises a host of additional and intriguing issues that are, for instance, analyzed in Chiu et al. (2019) and Fernández-Villaverde et al. (2020). The features and analysis in these papers could be imported here, but they would not appear to substantially change the key insights. Hence, we chose to focus entirely on the novel aspects arising from the interplay between the nominal features and price stability goals.

The rest of the paper is organized as follows. Section 2 reviews the related literature. Section 3 introduces our model. Section 4 presents the main analysis of the model, defines an equilibrium, and describes some of its fundamental properties. Section 5 discusses how the social optimum can be implemented. Section 6 deals with price stability and how it relates to the implementation of the social optimum. In Section 7, we discuss what may appear to be a natural resolution: the adjustment of the money supply in a state-contingent manner. Issues arising out of private-sector competition such as private investment or a competing private banking sector are taken up in Section 8. In Section 9, we analyze a token-based system and hybrid systems. Section 10 concludes.

\section{Related literature}

Our paper contributes to several strands of the literature. The three papers closest to ours are Diamond and Dybvig (1983), Skeie (2008), and Allen et al. (2014). First, we contribute to the literature of financial intermediation and bank fragility. Building on the seminal Diamond and Dybvig (1983) model, we stress the central bank's role in liquidity transformation when issuing a CBDC that allows depositors to share idiosyncratic liquidity risk. Similar to Diamond and Dybvig (1983), we study the microincentives of depositors to withdraw ("spend") from the bank. But unlike them, we employ nominal instead of real demand-deposit contracts, giving "the bank" an additional tool -the price level- to prevent runs.

Nominal demand-deposit contracts have previously been considered by Allen and Gale (1998), Skeie (2008), Allen et al. (2014), Leiva and Mendizábal (2019), and Andolfatto et al. (2020), among others. In Skeie (2008), large withdrawals of nominal deposits can lead to an increase in the price level, reducing the real allocation and deterring runs. In a similar model, Allen et al. (2014) show that optimal risk-sharing can be achieved via nominal contracts, but 
their setting cannot exclude runs. In particular, compare their Section 4.4 to our Lemma 5.2. In their case, the price level reacts passively and cannot be fine-tuned to the agent's spending decisions. As we mentioned above, in both Skeie (2008) and Allen et al. (2014), the "real" side is arising from the interplay between workers and entrepreneurs (and their customers), leaving the nominal side to the banking system and the central bank. Finally, Andolfatto et al. (2020) incorporate Diamond-Dybvig financial intermediation into the new monetarist model of Lagos and Wright (2005).

Unlike in all these papers, in our framework, the central bank is a strategic player that observes withdrawals and, as a response, determines the real goods supply to alter either the depositors' incentives to withdraw or the price level according to its objectives. Therefore, we can show that the central bank can always implement the efficient allocation in dominant strategies, and runs no longer occur. Since implementation in dominant strategies requires giving up price stability, we can also discuss the flip side of this result. We further differ from the literature above by considering a more stylized model, abstracting from private banks and firms. In our framework, the central bank takes over the activity of real investment, financial intermediation, and the management of the money supply.

Second, we contribute to a growing literature on the macroeconomic implications of introducing a CBDC. Berentsen (1998) is perhaps the first analysis of the monetary policy implications of digital money. Chiu et al. (2019) discuss issues regarding the competition with and support of private banks. Keister and Sanches (2019) explore how the presence of a CBDC affects the liquidity premium on bank deposits and, through it, investment. Böser and Gersbach (2019a) gauge the implications of CBDCs for banking panics. Böser and Gersbach (2019b) show that the introduction of a CBDC transfers default risk to the central bank when a CBDC competes with private deposits. Fernández-Villaverde et al. (2020) demonstrate that competition for deposits between private banks and the central bank can lead to a deposit monopoly at the central bank when commercial banks cannot commit. Skeie (2019) analyzes inflation-driven digital currency runs in a nominal model where a private digital currency competes with a CBDC. In contrast to this strand of the literature, our analysis abstracts from competition between a CBDC and deposits at private banks, respectively a CBDC and private digital currency, by modeling the central bank as the monopolistic provider of demand deposits. Brunnermeier and Niepelt (2019) derive an equivalence result of allocations when introducing a CBDC if the central bank commits to 
redepositing $\mathrm{CBDC}$ funds in private banks. In comparison, we are more explicit about the micro incentives of agents to run on the central bank. Ferrari et al. (2020) discuss monetary policy transmission in a two-country DSGE model when introducing a CBDC. In our model, we focus on one country and do not feature firms, other financial agents, or assets. Instead, we focus on the depositors' microincentives to (not) run on the central bank.

Lastly, we contribute to the growing literature on cryptoeconomics that analyzes the price and exchange rate implications of crypto mining (Choi and Rocheteau, 2020; Garratt and van Oordt, 2019; Huberman et al., 2017; Prat and Walter, 2018), the micro and macroeconomics of blockchain (Amoussou-Guenou et al., 2019; Biais et al., 2019a,b; Ebrahimi et al., 2019; Leshno and Strack, 2020; Saleh, 2020) and token issuance (Cong et al., 2020; Li and Mann, 2020; Prat et al., 2019), and the macroeconomic implications of cryptocurrencies via currency competition (Benigno, 2019; Benigno et al., 2019; Fernández-Villaverde and Sanches, 2019; Schilling and Uhlig, 2019). Our paper abstracts from the existence of competing digital currencies and assumes full functionality of the CBDC account and ledger system.

\section{The basic framework}

Our framework builds on the classical Diamond and Dybvig (1983) model of banking. Time is discrete with three periods $t=0,1,2$. There is a $[0,1]$-continuum of agents, each endowed with 1 unit of a real consumption good in period $t=0$. Agents are symmetric in the initial period, but can be of two types in period 1: patient and impatient. Impatient agents value consumption only in period 1 . In contrast, patient agents value consumption in period $t=2$. An agent is impatient with likelihood $\lambda \in(0,1)$ and otherwise is patient. The agent's type is randomly drawn at the beginning of period 1 and types are private information. Since we have a continuum of agents, there is no aggregate uncertainty about the measure of patient and impatient types in the economy. Thus, $\lambda$ also denotes the share of impatient agents. Preferences are represented by a strictly increasing, strictly concave, and continuously differentiable utility function over consumption $u(\cdot) \in \mathbb{R}$. We further assume a relative risk aversion, $-x \cdot u^{\prime \prime}(x) / u^{\prime}(x)>1$, for all consumption levels $x \geq 0$.

There exists a long-term production technology in the economy. For each unit of the good invested in $t=0$, the technology yields either 1 unit at $t=1$ or $R>1$ units at $t=2$. Additionally, there is a storage technology between periods 1 and 2, yielding 1 unit of the 
good in $t=2$ for each unit invested in $t=1$. All agents can access both technologies. Let $x_{1} \geq 0$ denote the agent's real consumption when deciding to spend (or "withdraw") at $t=1$, and let $x_{2} \geq 0$ denote the agent's consumption when spending at $t=2$.

\section{$3.1 \quad$ Optimal risk-sharing}

Following Diamond and Dybvig (1983), we derive, first, the optimal allocation. The social planner collects and invests the aggregate endowment in the long technology. Given that all agents behave according to their type, the social planner maximizes ex-ante welfare

$$
W=\lambda u\left(x_{1}\right)+(1-\lambda) u\left(x_{2}\right)
$$

by choosing $\left(x_{1}, x_{2}\right)$, subject to the feasibility constraint $\lambda x_{1} \leq 1$, and the resource constraint $(1-\lambda) x_{2} \leq R\left(1-\lambda x_{1}\right)$. The interior first-order condition for this problem implies that the optimal allocation $\left(x_{1}^{*}, x_{2}^{*}\right)$ satisfies:

$$
u^{\prime}\left(x_{1}^{*}\right)=R u^{\prime}\left(x_{2}^{*}\right)
$$

Given our assumptions, the resource constraint binds in the optimum

$$
R\left(1-\lambda x_{1}^{*}\right)=(1-\lambda) x_{2}^{*}
$$

This condition, together with equation (2), uniquely pins down $\left(x_{1}^{*}, x_{2}^{*}\right)$ and delivers the familiar optimal deposit contract in Diamond and Dybvig (1983). Together with $R>1$ and the concavity of $u(\cdot)$, equation (2) implies that the optimal consumption of patient agents is higher than the consumption of impatient ones: $x_{1}^{*}<x_{2}^{*}$.

Moreover, the depositors' relative risk-aversion exceeding unity and the resource constraint yield $x_{1}^{*}>1$ and $x_{2}^{*}<R .^{2}$

Diamond and Dybvig (1983) show that a demand-deposit contract can implement the

\footnotetext{
${ }^{2}$ Following the proof in Diamond and Dybvig (1983),

$$
R u^{\prime}(R)=u^{\prime}(1)+\int_{1}^{R} \frac{\partial}{\partial x}\left(x \cdot u^{\prime}(x)\right) d x=u^{\prime}(1)+\int_{1}^{R}\left(x \cdot u^{\prime \prime}(x)+u^{\prime}(x)\right) d x<u^{\prime}(1)
$$

by $-x \cdot u^{\prime \prime}(x) / u^{\prime}(x)>1$ for all $x$.
} 
efficient allocation. A key feature of their analysis is the use of a "real" demand deposit contract (i.e., a contract that promises to pay out goods in future periods). Due to a maturity mismatch between real long-term investment and real deposit liabilities, the Diamond and Dybvig (1983) environment, however, also features a bank run equilibrium under which the social optimum is not implemented. Our main contribution is to show that a nominal contract can lead to the implementation of the efficient allocation in dominant strategies. In other words, runs do not occur along the equilibrium path. The key mechanism is that the central bank can set the price level, thereby controlling the wedge between real longterm investment and nominal deposit liabilities. The implementation in dominant strategies comes at a price, requiring flexibility of the price level.

\section{A nominal economy}

Consider now an economy with a social planner that uses nominal contracts to implement the efficient allocation.

Nominal contracts. The planner offers contracts in a unit of account for which it is the sole issuer. Because central banks have a monopoly on currency, the planner in our analysis can be equated with the central bank or any other monetary authority with the ability to issue currency. In this paper, we refer to the unit of account as a central bank digital currency (CBDC) or digital euros. Agents who sign a contract with the central bank hand over their real goods endowment and receive CBDC balances in return. The most straightforward interpretation of our environment is to think of a CBDC as an accountbased electronic currency in the sense of Barrdear and Kumhof (2016) and Bordo and Levin (2017), i.e., to think of a CBDC as being akin to a deposit account at the central bank. In Section 9, we show that the results of our paper largely carry over to a token-based system or hybrid systems. Agents can spend their CBDC balances by transferring them to other agents in exchange for goods. As with physical euros, we impose the constraint that agents cannot hold negative amounts of a CBDC. v Timing. At $t=0$, the central bank creates an empty account, i.e., a zero-balance CBDC account, for each agent in the economy. Then, each agent agrees to invest her unit endowment of the good in exchange for $M>0$ units of digital euros, credited to that agent's account. Next, the central bank invests all goods in the long-term technology. 
In $t=1$, agents learn their type and decide whether to spend their CBDC balances $M$, that is, either to withdraw them or to roll them over. The central bank contract imposes the constraint that an agent either spends all her balances or no balance at all. Because types are unobservable, the central bank cannot discriminate between patient and impatient agents to deny a patient agent access to her balances. Let $n \in[0,1]$ denote the share and measure of agents who decide to spend in $t=1$. The central bank observes $n$ and then decides on the fraction $y=y(n)$ of technology to liquidate, selling that amount in the goods market at the unit price $P_{1}$. Notice that through the resource constraint, early liquidation of technology reduces the remaining investment and, hence, the supply of goods in $t=2$. That is, there is a real payoff externality, and the central bank's liquidation choice in $t=1$ determines the real supply of goods for both of the periods $t=1$ and $t=2$. Given $n$, the central bank also chooses a nominal interest rate $i=i(n)$ to be paid in period 2 on the remaining CBDC balances. Each digital euro held at the end of $t=1$ turns into $1+i(n)$ digital euros at the beginning of $t=2$. Notice that $i(n) \geq-1$, given that agents cannot hold negative amounts of digital euros.

In $t=2$, the remaining $1-n$ depositors each have $(1+i) M$ digital euros to spend on goods in the market at a price $P_{2}$. The remaining investment in the technology matures so that the central bank supplies $R(1-y(n))$ units of goods in exchange for money balances. Figure 2 summarizes this timing.

Definition 1. A central bank policy is a triple $(M, y(\cdot), i(\cdot))$, where $y:[0,1] \rightarrow[0,1]$ specifies the central bank's liquidation policy and $i:[0,1] \rightarrow[-1, \infty)$ is the interest rate policy for every possible spending level $n \in[0,1]$.

Notice that $M$ itself is not state-contingent. The logic here is that, traditionally, 1 dollar today is 1 dollar tomorrow: we maintain that tradition with that assumption here. In Section 7, we discuss an extension where we allow $M$ to be state-contingent as well.

Market clearing. In periods 1 and 2, agents spend their money balances for goods in a Walrasian market. The market-clearing conditions are:

$$
\begin{aligned}
n M & =P_{1} y(n) \\
(1-n)(1+i(n)) M & =P_{2} R(1-y(n)),
\end{aligned}
$$

which take the form of the quantity theory equation in each period. Given aggregate spending 


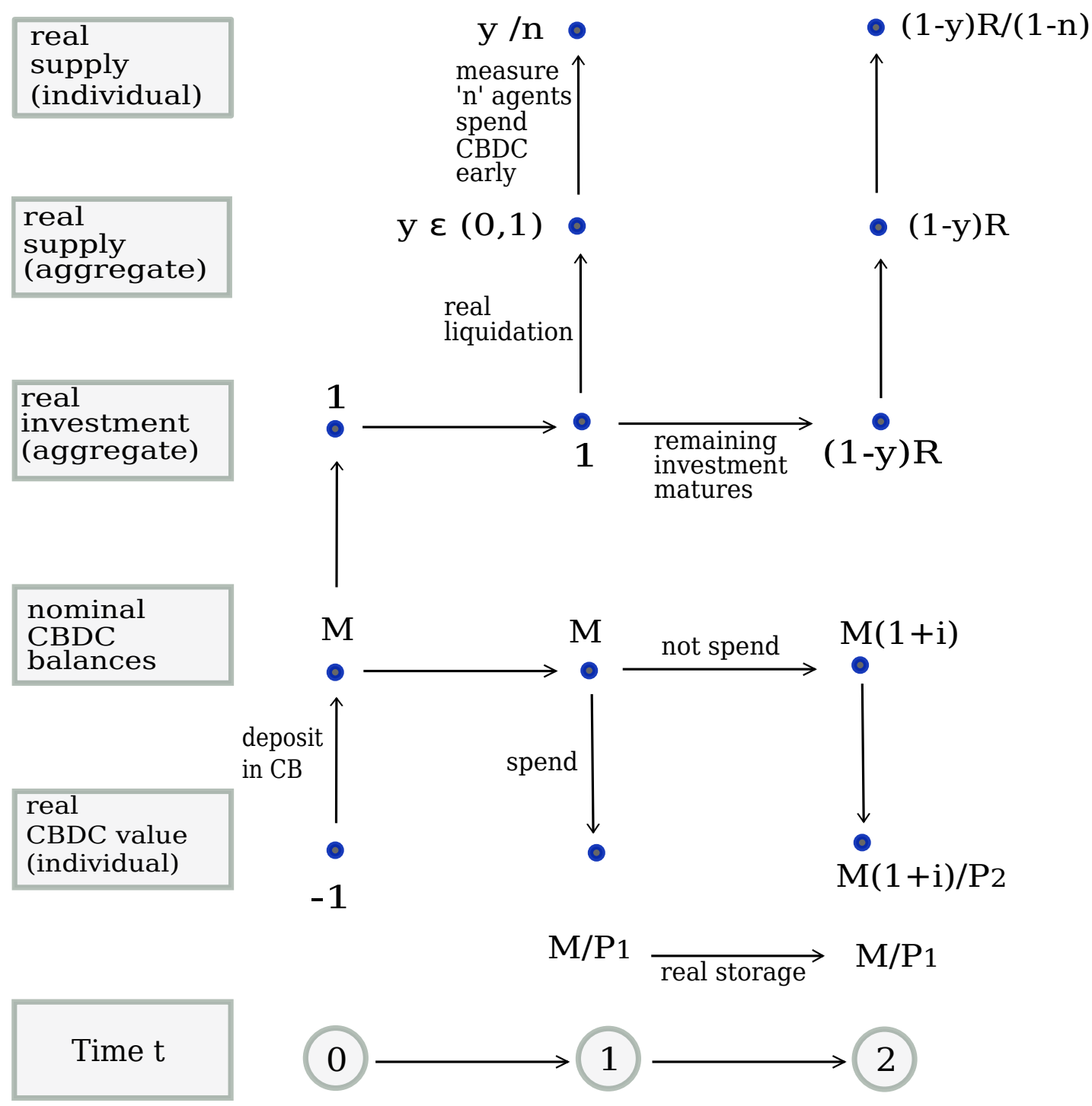

Figure 2: Nominal and real investment and contracts

$n$ in $t=1$ and the central bank's policy, these conditions determine the price level, $P_{1}=P_{1}(n)$ and $P_{2}=P_{2}(n)$, in each period:

$$
\begin{aligned}
& P_{1}(n)=\frac{n M}{y(n)} \\
& P_{2}(n)=\frac{(1-n)(1+i(n)) M}{R(1-y(n))} .
\end{aligned}
$$


The central bank chooses the initial money supply before learning the measure of withdrawals in the intermediate period. The central bank, however, controls the goods supply in the Walrasian market, which is chosen conditional on the measure of withdrawals. As a result, the central bank can control the price level in period $1 .^{3}$ The nominal interest rate allows the central bank to control the price level in period 2 independently of the price level in period 1. Because the intermediary is the central bank with a monopoly on the unit of account in which contracts are denominated, the liquidation policy is flexible and becomes a monetary policy tool.

Implied real contract. The real value when spending CBDC balances in $t=1$ equals

$$
x_{1}=\frac{M}{P_{1}},
$$

while the real value when spending balances in $t=2$ equals

$$
x_{2}=\frac{(1+i(n)) M}{P_{2}} .
$$

Aggregate spending $n$ and the liquidation policy $y(n)$ jointly determine the allocation of goods via the market-clearing conditions. The real allocations when spending in $t=1$ versus $t=2$ can therefore be rewritten as

$$
\begin{aligned}
& x_{1}(n)=\frac{y(n)}{n} \\
& x_{2}(n)=\frac{1-y(n)}{1-n} R .
\end{aligned}
$$

Because all agents that spend CBDC in the same period have the same nominal income, the real goods supply $y(n)$ is equally distributed across all spending agents in period 1 , and the supply $R(1-y(n))$ is equally allocated to all spending agents in period $2 .{ }^{4}$

To summarize: in $t=0$, the central bank announces and commits to a policy $(M, y(\cdot), i(\cdot))$, pinning down a spending-contingent real goods supply and an offer to a nominal contract $(M, M(1+i(\cdot)))$ in exchange for 1 unit of the good. All consumers accept the contract and

\footnotetext{
${ }^{3} \mathrm{~A}$ private bank, in contrast, would need to take $P_{1}, P_{2}$ as given, which together with the observation $n$ implies a unique liquidation $y\left(n, P_{1}\right)$.

${ }^{4}$ These equations remain intuitive even if $y(n)=0$ or $y(n)=1$. Therefore, we assume that they continue to hold, despite one of the price levels being potentially ill-defined or infinite.
} 
the policy, meaning they have the option to spend either $M$ digital euros in period 1 or $M(1+i(n))$ digital euros in period 2 , for every possible level of aggregate spending $n \in[0,1]$. We discuss voluntary participation in contracts in Section 8.

In $t=1$, the aggregate spending level $n$ is realized. Finally, the central bank's policy, together with the market-clearing conditions, results in the real consumption amounts $\left(x_{1}(n), x_{2}(n)\right)=\left(\frac{M}{P_{1}}, \frac{M(1+i(n))}{P_{2}}\right)=\left(\frac{y(n)}{n}, \frac{1-y(n)}{1-n} R\right)$. Notice that the central bank is fully committed to carry through with its policy $(M, y, i)$, regardless of which $n$ obtains and independently of the implications for the price levels $\left(P_{1}, P_{2}\right)$. We, therefore, define

Definition 2. A commitment equilibrium consists of a central bank policy $(M, y(\cdot), i(\cdot))$, aggregate spending behavior $n \in[0,1]$ and price levels $\left(P_{1}, P_{2}\right)$ such that:

(i) The spending decision of each individual consumer is optimal given aggregate spending decisions $n$, the announced policy $(M, y(\cdot), i(\cdot))$, and price levels $\left(P_{1}, P_{2}\right)$.

(ii) Given aggregate spending $n$, the central bank provides $y(n)$ goods and sets the nominal interest rate $i(n)$.

(iii) Given $(n, y(n), M)$, the price level $P_{1}$ clears the market in $t=1$.

Given $(n, y(n), i(n), M)$, the price level $P_{2}$ clears the market in $t=2$.

As a particular consequence of this equilibrium concept, the price levels $\left(P_{1}, P_{2}\right)$ flexibly adjust to the aggregate spending realization and the announced central bank policy.

\section{Implementation of the social optimum}

In our model, the implementation of the social optimum $\left(x_{1}^{*}, x_{2}^{*}\right)$ is of particular interest to the central bank. Given the preferences and technology that we postulated above, only the real allocation of goods matters to the two types of agents. There is, consequently, no additional motive for the monetary authority to keep prices stable.

However, focusing only on real allocations is a narrow perspective. There is a vast literature arguing in favor of central banks keeping prices stable or setting a goal of low and stable inflation for reasons that are absent from our model. For instance, stable prices minimize the misallocations created by nominal rigidities as in Woodford (2003). And having to 
hold cash to accomplish transactions, such as in cash-in-advance or money-in-utility models, creates a whole range of distortions that can be minimized by deft management of the price level (think about the logic behind the Friedman rule). Rather than extending the model to include these considerations, which would complicate the analysis for an uncertain benefit, we shall proceed by discussing the tradeoffs between achieving the optimal real allocation of consumption and the implications of such an effort for the stability of prices.

Runs on the central bank. The first important property of the equilibrium defined above is that a nominal contract, per se, does not rule out the possibility of a run on the central bank. Since impatient agents only care for consumption in $t=1$, every equilibrium will exhibit aggregate spending behavior of at least $\lambda$, implying $n \geq \lambda .{ }^{5}$ Patient agents, on the other hand, spend their CBDC balances strategically in $t=1$ or $t=2$. They spend in $t=1$ if they believe that the central bank policy implies $x_{1}>x_{2}$. In that case, patient agents will use the storage technology to consume $x_{1}$ in period 2. Otherwise, patient agents will find it optimal to wait until the final period. We say,

Definition 3 (Central Bank Run). A run on the central bank occurs if patient agents also spend in $t=1, n>\lambda$.

In a bank run, the central bank is not running out of the item that it can produce freely (i.e., it is not running out of digital money). This feature will distinguish the run equilibrium here from the bank run equilibrium in Diamond and Dybvig (1983), in which a commercial bank prematurely liquidates all of its assets to satisfy the demand for withdrawals in period 1 , therefore, ultimately running out of resources. If $n>\lambda$, the central bank is confronted with a run on deposits. As we will see, the real consequences of a run on the central bank with nominal contracts can be similar to its counterpart in the model with real contracts. However, we shall demonstrate that the central bank's ability to avert a run is necessarily tied to its monopoly on currency and the implementation of a nominal contract. Importantly, by equations (11) and (12), a patient agent's optimal decision whether to run on the central bank, to spend or not, depends on the central bank's choices only through the liquidation policy $y(\cdot)$ and not via the nominal elements $M$ and $i(n)$. By our equilibrium definition, the aggregate spending behavior $n$ has to be consistent with optimal individual choices. These considerations imply the following lemma.

\footnotetext{
${ }^{5}$ When $y(n)=0$, impatient agents are indifferent between spending and not spending. To break ties, we assume that they spend their CBDC balances in $t=1$.
} 
Lemma 5.1. Given the central bank policy $(M, y(\cdot), i(\cdot))$,

(i) The absence of a run, $n=\lambda$, is an equilibrium only if $x_{1}(\lambda) \leq x_{2}(\lambda)$.

(ii) A central bank run, $n=1$, is an equilibrium if and only if $x_{1}(1) \geq x_{2}(1)$.

(iii) A partial run, $n \in(\lambda, 1)$, occurs in equilibrium if and only if patient agents are indifferent between either action, requiring $x_{1}(n)=x_{2}(n)$.

This lemma fully characterizes the range of equilibria, given the implied real allocation of a central bank policy. But how can policy attain the first-best allocation?

\subsection{Implementation of the optimum via liquidation policy}

By $\left(x_{1}^{*}, x_{2}^{*}\right)=\left(\frac{y^{*}}{\lambda}, \frac{R\left(1-y^{*}\right)}{1-\lambda}\right)$, the feasibility constraint $y \in[0,1]$, and the optimality conditions in Section 3.1, the implementation of the socially optimal allocation requires a liquidation policy

$$
y^{*}(\lambda)=x_{1}^{*} \lambda \in(\lambda, 1]
$$

given that only impatient types spend. Similarly to Diamond and Dybvig (1983), the resource constraint $y \in[0,1]$ and $x_{1}^{*}>1$ imply that the socially optimal allocation is not feasible when all agents spend. The implied price level when $n$ agents spend equals $P_{1}^{*}(n)=\frac{n M}{\lambda x_{1}^{*}}$. These results confirm our assertion at the start of this section that the social optimum is independent of price level stability. Combining the previous derivation with Lemma 5.1, we arrive at the following lemma.

Lemma 5.2. The central bank policy $(M, y(\cdot), i(\cdot))$ implements the social optimum $\left(x_{1}^{*}, x_{2}^{*}\right)$ in dominant strategies if the central bank

(i) sets $y(\lambda)=y^{*}$ for any $n \leq \lambda$.

(ii) sets a liquidation policy that implies $x_{1}(n)<x_{2}(n)$ for all $n>\lambda$.

The real allocation to agents and, thus, their incentives to spend or not depend on the central bank policy $(M, y(\cdot), i(\cdot))$ only through the liquidation policy $y(\cdot)$. Given that only impatient agents are spending (i.e., $n=\lambda$ ), then a policy choice with $y(\lambda)=y^{*}$ implements the social optimum. That is, there is a multiplicity of monetary policies that implement the 
first-best since the pair $(M, i(\cdot))$ is not uniquely pinned down. While the pair $(M, i(\cdot))$ does not affect depositors' incentives, it has an impact on prices via equations (7) and (8).

Second, thanks to the existence of the storage technology, patient agents can -but do not have to- spend their CBDC balances at time two. Spending at time two is dominant only if for every possible spending level $n$ the real allocation at time two exceeds the allocation at $t=1$.

The central bank internalizes depositors' decision making. Since it observes aggregate spending behavior $n$ before it liquidates any asset, the central bank is not committed to liquidating $y^{*}$ if patient agents are also spending. Condition (ii) of this lemma corresponds to the classic incentive-compatibility constraint in the bank run literature: since expectations are rational, in $t=1$, depositors correctly anticipate the central bank policy that follows spending behavior $n$. To deter patient agents from spending, the central bank can threaten to implement a liquidation policy $y(\cdot)$ that makes spending non-optimal ex-post, i.e., so that $x_{1}(n)<x_{2}(n)$ for $n \in(\lambda, 1]$. If the monetary authority can credibly threaten patient agents by setting such a liquidation policy, it deters them from spending ex-ante, and a central bank run does not occur in equilibrium. Therefore, in the unique equilibrium, only impatient agents spend, all patient agents roll over, and the social optimum is always attained.

The central bank implements "spending late" as the dominant equilibrium strategy for patient agents by fine-tuning the real goods supply via its liquidation policy, i.e., by making real asset liquidation spending-contingent.

Definition 4. We call a liquidation policy $y(\cdot)$ "run-deterring" if it satisfies

$$
y^{d}(n)<\frac{n R}{1+n(R-1)}, \quad \text { for all } n \in(\lambda, 1]
$$

Such a liquidation policy implies that "roll over" is ex-post optimal $x_{1}(n)<x_{2}(n)$ even though patient agents are withdrawing $n \in(\lambda, 1]$.

The implementation of a run-deterring policy is only possible because the contracts between the central bank and the agents are nominal. The liquidation of investments in the real technology is at the central bank's discretion, thereby controlling the real goods supply and, for a given spending level, the real allocation in either time period. A spending-contingent liquidation policy implies a spending-contingent price level. In the case of real contracts 
between a private bank and depositors such as in Diamond and Dybvig (1983), in contrast, the real claims of the agents are fixed already in $t=0$, thus pinning down a liquidation policy for every measure of aggregate spending $n$. In the case of large withdrawals, rationing must occur. Similarly, in the case of nominal contracts between a private bank and depositors, the private bank has to take the price level as given, which then again pins down the liquidation policy. Alternatively, the price level adjusts via market clearing to high aggregate nominal spending (Skeie, 2008), while here it can serve as a strategic control variable.

As the main result of this paper,

Corollary 5 (Trilemma part I - No price stability). Every policy choice $(M, y(\cdot), i(\cdot)), n \in$ $[0,1]$ with

$$
y(\lambda)=y^{*} \text { and } y^{d}(n)<\frac{n R}{1+n(R-1)}, \quad \text { for all } n \in(\lambda, 1]
$$

deters central bank runs and implements the social optimum in dominant strategies. Such a deterence policy choice requires the interim price level $P_{1}(n)$ to exceed the withdrawaldependent bound:

$$
P_{1}(n)>\frac{M}{R}(1+n(R-1)), \quad \text { for all } n \in(\lambda, 1] .
$$

Under a credible liquidation policy (15) all agents have a dominant strategy to spend if and only if the agent is impatient; otherwise they wait. Thus, under rational behavior, runs do not occur, and by $y(\lambda)=y^{*}$ the social optimum always obtains. That is, a strategic real supply shock enforced by the central bank causes a demand shock to CBDC spending that deters runs.

The implementation, however, comes at a price. To attain feasibility of a run-deterring policy $y(\cdot)$, the central bank has to sacrifice price stability. By condition (16), the more agents spend, the larger the required price level threat to deter runs. The threat has to be credible to deter runs ex-ante. Agents have to believe that ex-post the central bank will give up price stability if realized spending behavior is excessive. Only then do runs and inflation not occur on the equilibrium path.

In Diamond and Dybvig (1983), we learned the dilemma that offering the optimal amount of risk-sharing via demand-deposit contracts requires private banks to be prone to runs. Thus, a bad bank run equilibrium also exists. Our result brings this dilemma to the next level. If the bank is a central bank equipped with the power to set price levels and control 
the real goods supply, then optimal risk-sharing can be implemented in dominant strategies such that a bank run never occurs, but only at the expense of price stability.

Observe that by the optimality conditions and the resource constraint, $y^{*}<\frac{\lambda R}{1+\lambda(R-1)}$ holds and that the upper bound for $y^{d}(n)$ is increasing in $n$. Therefore, the constant liquidation policy

$$
y(n) \equiv y^{*}
$$

implements the socially optimal equilibrium in dominant strategies. However, there exist other liquidation policies that can accomplish the same result. The policy (17) delivers the same result as does the classic suspension-of-convertibility option, which is known to exclude bank runs in the Diamond-Dybvig world.

There is a subtle but essential difference, though, between suspension and our liquidation policy. Suspension of convertibility requires the bank to stop paying customers who arrive after the fraction $\lambda$ of agents have withdrawn. By contrast, in our environment, there is no restriction on agents to spend their digital euros in period 1, and there is no suspension of accounts. Instead, it is the supply of goods offered for trade against those digital euros and the resulting change in the price level that generate the incentives for patient agents to prefer to wait. This reasoning also implies that, in our model, (nominal) deposit insurance will not deter agents from running on the central bank.

More concretely, low liquidation and thus supply implies that the price level $P_{1}$ is pushed above an upper bound that is increasing in the aggregate spending. ${ }^{6}$ The low liquidation policy, on the other hand, deters large spending ex-ante, such that the high price level (16) is a threat that is realized only off-equilibrium. But each time we have an off-equilibrium threat, we should worry about the possibility of time inconsistency. In comparison with the classical treatment of time inconsistency in Kydland and Prescott (1977), the concern here is not that the central bank will be tempted to inflate too much, but that it would be tempted to inflate too little. The central bank can avoid suboptimal allocations by committing to let inflation grow whenever necessary. A similar concern appears in models with a zero lower bound on nominal interest rates. Eggertsson and Woodford (2003) have shown that a central

\footnotetext{
${ }^{6}$ Our result resembles Theorem 4 in Allen and Gale (1998) and has a similar intuition. In Allen and Gale (1998), a central bank lends to a representative bank an interest-free line of credit to dilute the claims of the early consumers so that they bear a share of the low returns to the risky asset. In their environment, private bank runs are required to achieve the first-best risk allocation.
} 
bank then wants to commit to keeping interest rates sufficiently low for sufficiently long, even after the economy is out of recession, to get the economy off the zero lower bound (see also Krugman, 1998, for an early version of this idea). But once the economy is away from the zero lower bound, there is an incentive to renege on the commitment to lower interest rates and avoid an increase in the price level.

In our model, we assume that the central bank fully commits such that the threat is credible. But what if the central bank is concerned with price stability and, therefore, refuses to induce a high price level?

\section{The classic policy goal: Price level targeting}

There are many possible reasons why central banks view the stabilization of price levels or, more generally, inflation rates as one of their prime objectives. The model here should be viewed as part of a larger macroeconomic environment, where price stability must be taken into account. The task at hand, then, is to examine how price stability imposes constraints on central bank policy. In particular, we will document the existence of deep tensions between the three objectives of attaining the first-best outcome, deterring central bank runs, and maintaining price stability.

Addressing the time-inconsistency problem above requires the introduction of an objective function for the central bank. Given an objective function for the central bank, a time-consistent equilibrium is a commitment equilibrium such that the central bank policy $(M, y(n), i(n))$ and the resulting price levels $\left(P_{1}(n), P_{2}(n)\right)$ maximize the central bank's objective function for every value $n \in[0,1]$. A particular objective is that the central bank pursues price stability above everything else. We shall distinguish between two versions of the objective of price stability: full price stability and partial price stability. Let us start by analyzing the former.

\subsection{Full price stability}

Definition 6. We call a central bank policy

(i) $P_{1}$-stable at level $\bar{P}$, if it achieves $P_{1}(n) \equiv \bar{P}$ for the price level target $\bar{P}$, for all spending behavior $n \in[\lambda, 1]$. 
(ii) price-stable at level $\bar{P}$, if it achieves $P_{1}(n)=P_{2}(n) \equiv \bar{P}$ for the price level target $\bar{P}$, for all spending behavior $n \in[\lambda, 1]$.

In our definition, price stability here is treated as a mandate and commitment to the price level $\bar{P}$ even for off-equilibrium realizations of $n$. From the definition, price stability at some level $\bar{P}$ implies $P_{1}$ stability at $\bar{P}$. Hence, the second price stability criterion is stronger.

Definition 7. Given a price goal $\bar{P}$, we call a commitment equilibrium a

- $P_{1}$-price-commitment equilibrium, if the central bank policy is $P_{1}$-stable at level $\bar{P}$

- price-commitment equilibrium, if the central bank policy is price-stable at level $\bar{P}$

What constraints does the price stability objective impose on central bank policy?

Proposition 8 (Policy under Full Price Stability). A central bank policy is:

(i) $P_{1}$-stable at level $\bar{P}$, if and only if its liquidation policy satisfies:

$$
y(n)=\frac{M}{\bar{P}} n, \text { for all } n \in[0,1]
$$

implying a real interim allocation:

$$
x_{1}(n) \equiv \bar{x}_{1}=\frac{M}{\bar{P}} \leq 1
$$

(ii) A central bank policy is price-stable at level $\bar{P}$, if and only if its liquidation policy satisfies equation (18), its price level satisfies (19), and its interest policy satisfies:

$$
i(n)=\frac{\frac{\bar{P}}{M}-n}{1-n} R-1 .
$$

A price-stable liquidation policy (18) requires asset liquidation in constant proportion to aggregate spending for all $n \in[0,1]$; see the green line in Figure 3 , where we plot $y(n)$ for partial versus full price-stable liquidation policies. As a consequence, individual real consumption $x_{1}$ is constant regardless of aggregate spending behavior, and cuts below 1 since, due to the resource constraint, the central bank cannot liquidate more than the entire investment. Hence, a price-stable liquidation policy excludes rationing or all kinds of suspension 
policies. By equation (19) and again due to the resource constraint, for a given money supply $M$, only price levels $\bar{P} \geq M$ can be $P_{1^{-}}$stable or price-stable. The slope of the liquidation policy is, thus, equal or below 1 . In other words, the rationing problem shows up indirectly through a lower bound on all possible price-stable central bank policies.

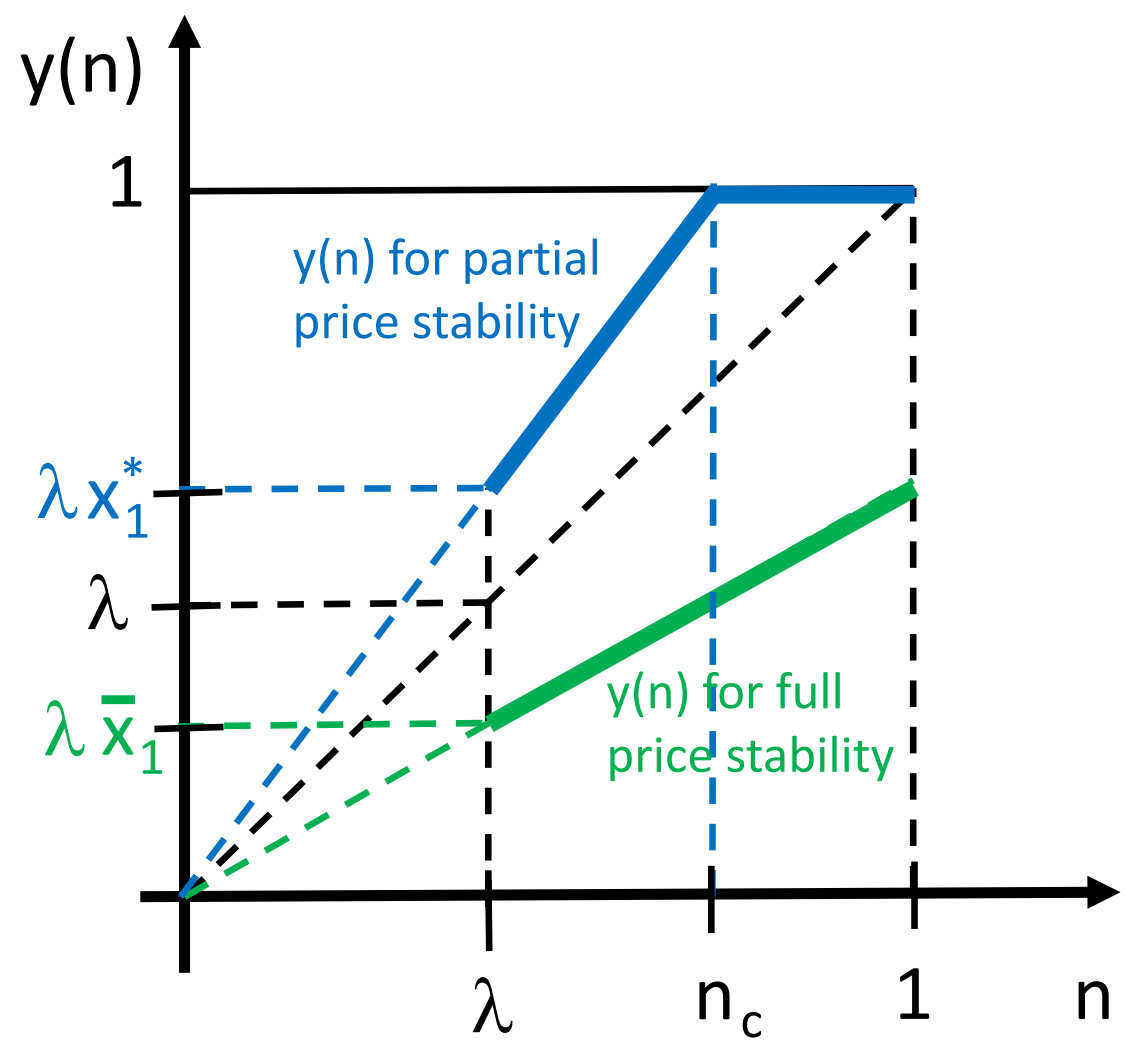

Figure 3: Partial vs. full price-stable liquidation policies

There is a caveat here. Should agents be able to operate the savings technology on their own, then they can always assure themselves a payoff of 1 in period $t=1$ for every good stored in period $t=0$. Thus, the only CBDC contract acceptable to these agents would be a "green line" coinciding with the 45-degree line and a slope of 1 . Slopes below 1 are agreeable, however, if the central bank is the only entity capable of operating this technology or the only entity capable of intermediation with operators of that technology.

Recall from Section 5, that the socially optimal allocation satisfies $x_{1}^{*}>1$, while from Proposition 8 a $P_{1}$ price-stable policy requires $x_{1} \leq 1$. Therefore, we can show the second 
part of our trilemma:

Corollary 9 (Trilemma part II - No optimal Risk-sharing). If the central bank commits to a $P_{1}$-stable policy, then:

(i) The socially optimal allocation is never implemented.

(ii) The no-run equilibrium is implemented in dominant strategies, i.e., there is a unique equilibrium in which only impatient agents spend, $n^{*}=\lambda$, and there are no central bank run equilibria.

(iii) If the central bank commits to a price-stable central bank policy, then the nominal interest rate is increasing in $n$ and non-negative $i(n) \geq 0$ for all $n \in[\lambda, 1]$.

Intuitively, no runs take place under a $P_{1}$-stable policy since the real allocation in $t=1$ is too low, causing all patient agents to prefer to spend late.

\subsection{Partial price stability}

While price stability and the absence of central bank runs may be desirable, the constraint (19), i.e., the failure to implement the socially optimal real allocation, is not. In particular, the implementation of the social optimum is impossible under complete price stability. Recall that optimal risk-sharing at $x_{1}^{*}>1$ triggers potential bank runs in models of the DiamondDybvig variety: thus, part (ii) of the proposition above should not be a surprise. Demanding price stability for all possible spending realizations of $n$ is thus too stringent: for sufficiently high spending levels of $n$, equation (18) exhausts the liquidation possibilities available to a central bank, as $y(n)$ cannot exceed 1 . We therefore examine a more modest goal: a central bank may still wish to assure price stability, but may deviate from its goal in times of crises. We capture this with the following definition.

Definition 10. A central bank policy is

(i) partially $P_{1}$-stable at level $\bar{P}$, if for all spending behavior $n \in[\lambda, 1]$, either the policy achieves $P_{1}(n)=\bar{P}$ for some price level target $\bar{P}$, or aggregate spending satisfies $n>\bar{P} / M$. In the latter case, we require full liquidation, $y(n)=1$. 
(ii) partially price-stable at level $\bar{P}$, if for all spending behavior $n \in[\lambda, 1]$, either the policy achieves $P_{1}(n)=P_{2}(n)=\bar{P}$ for some price level target $\bar{P}$, or aggregate spending satisfies $n>\bar{P} / M$. In the latter case, we require $y(n)=1$.

For a graphical illustration, see the blue line in Figure 3. Obviously, $P_{1}$-stable central bank policies are also partially $P_{1}$-stable, and price-stable central bank policies are also partially price-stable.

Definition 11. Given a price goal $\bar{P}$, we call a commitment equilibrium a

- partial $P_{1}$-price-commitment equilibrium, if the central bank policy is partially $P_{1}$-stable at level $\bar{P}$

- partial price-commitment equilibrium, if the central bank policy is partially pricestable at level $\bar{P}$

Recall that only price levels above the money supply $\bar{P} \geq M$ can attain full price stability. We therefore now concentrate on lower price levels $M>\bar{P}$, since attaining optimality requires $1<x_{1}^{*}=M / \bar{P}$. Nevertheless, we also encounter a (weaker) feasibility constraint for partially price-stable policies. Since the central bank cannot liquidate more than the entire asset, $y(n)=x_{1} n \in[0,1]$ for all $n \in[\lambda, 1]$, it faces the constraint $\lambda x_{1} \leq 1$. Feasibility, therefore, implies a lower bound on all possible partially stable price levels, $\bar{P} \geq \lambda M$. Furthermore, partial price stability restricts central bank policies:

Proposition 12 (Policy under Partial Price-Stability). Suppose that $M>\bar{P} \geq \lambda M$.

(i) A central bank policy is partially $P_{1}$-stable at level $\bar{P}$, if and only if its liquidation policy satisfies:

$$
y(n)=\min \left\{\frac{M}{\bar{P}} n, 1\right\} .
$$

(ii) For every partially $P_{1}$-stable central bank policy at level $\bar{P}$, there exists a critical aggregate spending level $n_{c} \equiv \frac{\bar{P}}{M} \in(0,1)$ such that

(ii.a) For all $n \leq n_{c}$, the price level is stable at $P_{1}(n)=\bar{P}$ and the real goods purchased per agent in period $t=1$ equal $x_{1}(n)=\bar{x}_{1}=\frac{M}{\bar{P}}>1$ while real goods purchased per agent in period $t=2$ equal $x_{2}(n)=R\left(1-\bar{x}_{1} n\right) /(1-n)$. 
(ii.b) For spending $n>n_{c}$, the real goods purchased per agent in period $t=1$ equal $x_{1}(n)=1 / n$ while $x_{2}(n)=0$ and the price level $P_{1}(n)$ proportionally increases with total spending $n: P_{1}(n)=M n$

(iii) A central bank policy is partially price-stable at $\bar{P}$, if and only if its liquidation policy satisfies equation (21) and its interest policy satisfies:

$$
i(n)=\frac{\bar{P}-n}{1-n} R-1, \quad \text { for all } n \leq n_{c}
$$

For $n>n_{c}$, there is no supply of real goods in $t=2$. Thus, $P_{2}$ and $i(n)$ are irrelevant.

(iv) For a partially price-stable central bank policy at $\bar{P}$, there exists a spending level

$$
n_{0}=\frac{R \frac{\bar{P}}{M}-1}{R-1}=\frac{R n_{c}-1}{R-1} \in\left[0, n_{c}\right),
$$

such that the nominal interest rate turns negative for all $n \in\left(n_{0}, n_{c}\right)$. For $R<M / \bar{P}$, the nominal interest rate is negative for all $n \in\left[0, n_{c}\right)$.

Proposition 12 reflects the central bank's capacity to keep the price level and the real interim allocation $x_{1}$ stable as long as spending remains below the critical level $n_{c}$. The stabilization of the price level requires liquidation of real investment proportionally to aggregate spending by factor $M / \bar{P}$. At the critical spending level $n_{c}$, the central bank is forced to liquidate the entire asset to maintain the price level $P_{1}$. Since the central bank cannot liquidate more than its entire investment, as spending exceeds the critical level $n_{c}$, price level stabilization via liquidation of real assets becomes impossible. For all spending behavior $n>n_{c}$, the real allocation to late spending agents is thus zero. The rationing of real goods implies that the price level has to rise and the real allocation declines in aggregate spending.

The spending level $n_{0}<n_{c}$ is the level at which the real allocation to early and late spenders is just equal

$$
x_{1}\left(n_{0}\right)=x_{2}\left(n_{0}\right)=\bar{x}_{1} .
$$

Notice that $x_{2}(n)$ declines in $n$ for $n \in\left[0, n_{c}\right]$. Thus, if fewer than measure $n_{0}$ of agents spend, not spending is optimal for patient agents. But for all spending realizations $n>n_{0}$, the allocation at $t=2$ undercuts the allocation at $t=1: x_{2}(n)<x_{1}(n)$, turning the real 
interest rate on the CBDC negative, and causing "spend early" to be a patient agent's optimal response to an aggregate spending behavior in excess of $n_{0}$. Consequently, self-fulfilling runs are possible as in Diamond and Dybvig (1983), and we obtain the following result as a corollary of Proposition 12:

Corollary 13 (Trilemma part III- Runs on the Central Bank (Fragility)). Under every partially $P_{1}$-stable central bank policy with $M>\bar{P} \geq \lambda M$, there is a multiplicity of equilibria:

(i) There exists a good equilibrium in which only impatient agents spend, $n^{*}=\lambda$. In that case, there is no run on the central bank, the social optimum is attained and the price level is stable at level $\bar{P}$.

(ii) There also exists a bad equilibrium in which a central bank run occurs, $n^{*}=1$, the social optimum is not attained, and the price level is unstable.

Proposition 12 is in marked contrast to Proposition 8. One could argue that when banking is interesting, i.e., $x_{1}^{*}>1$, then the goal of price stability induces the possibility of runs on the central bank, the necessity for negative nominal interest rates, and the abolishment of the price stability goal, if a run indeed occurs.

\section{Money supply policy or suspension of spending}

It is natural to ask why the central bank cannot resort to a much more classical monetary policy to resolve the trilemma and attain price stability: expansion or reduction of the money supply. In this section, let us then allow for the possibility that $M$ is state-contingent, i.e., $M$ is chosen as a function of aggregate spending $M=M(n)$ at $t=1$. Therefore, a central bank policy consists of three functions $(M(\cdot), y(\cdot), i(\cdot))$.

The analysis is now straightforward and easiest to explain for the case where the liquidation policy is not state-contingent, $y(n) \equiv y^{*}$. To maintain price stability at some level $\bar{P}$, market clearing demands

$$
n M(n)=\bar{P} y^{*}
$$

As a result, the total money balances spent in $t=1$ stay constant in $n$, implying

$$
n M(n) \equiv \lambda M(\lambda), \quad \text { for all } n \in[\lambda, 1]
$$


But spending per agent alters, as does the total money supply $M(n)$. That is, the central bank would have to commit itself to reduce the quantity of money in circulation in response to a demand shock encapsulated in $n$ : the more people go shopping, the lower are individual money balances. With the policy $(25), y(n) \equiv y^{*}$ and $i(n) \equiv i^{*}$ chosen so that $P_{2}=\bar{P}$, the central bank can now achieve full price stability, efficiency and financial stability. The CBDC trilemma appears to be resolved. There are several ways of thinking about this.

State-contingent money supply. A first approach is to make the amount of CBDC balances available for shopping in $t=1$ state-contingent. Having such CBDC accounts with random balances is an intriguing possibility: it is quite impossible with paper money but fairly straightforward with electronic forms of currency. A different interpretation of this approach is to think in terms of a state-contingent nominal interest rate paid on CBDC accounts between $t=0$ and $t=1$. One should recognize that both of these routes are a bit odd, and contrary to how we usually treat money and interest rates. As for money, a dollar today is a dollar tomorrow: changing that amount in a state-contingent fashion probably risks severely undermining the trust in the monetary system, and trust is key for maintaining a fiat currency. As for interest rates, it is commonly understood that interest rates are agreed upon before events are realized in the future. A state-contingent interest rate turns accounts into risky and equity-like contracts, likewise undermining trust in the safety of the system.

Helicopter drops. A third way to think about the state-contingent nature of $M$ corresponds to a classic monetary injection in the form of state-contingent lump-sum payments ("helicopter drops") $M(n)-\bar{M}$ (or taxes, if negative), compared to some original baseline $\bar{M}$. If one wishes to insist that $M(n)-\bar{M} \geq 0$, i.e., only allowing helicopter drops, then the central bank would choose $\bar{M} \leq M(1)$ as payment for goods in period $t=0$ and thus always distribute additional helicopter money in the "normal" case $n=\lambda$ in period 1 . Notice that distributional issues would arise in richer models, where agents are not coordinating on the same action, thereby distorting savings incentives.

Suspension of spending. With an account-based CBDC, there is an additional and rather drastic policy tool at the disposal of the central bank: the central bank can simply disallow agents to spend (i.e., transfer to others) more than a certain amount on their account. In other words, the bank can impose a "corralito" and suspend spending. This policy is different from the standard suspension of liquidation, as the amount of goods to-be-made 
available is a policy-induced choice that still exists separately from the suspension of spending policy. Notice also that "suspension of spending" should perhaps not be called "suspension of withdrawal." Since there are only CBDC accounts and they cannot be converted into something else, the amounts can only be transferred to another account. With the suspension of spending policy, the central bank could arrange matters in such a way that not more than the initially intended amount of money $\lambda M(\lambda)$ will be spent in period 1 ; see equation (26). In practice, the central bank would then either take all spending requests at once and, if the total spending requests exceeded the overall threshold, impose a pro-rata spending limit. Alternatively, it could arrange and work through the spending requests in some sequence (first-come-first-served), thereby possibly imposing different limits depending on the position of a request in that queue.

Monetary neutrality. Last but not least, a state-contingent money supply cannot replace the central bank's liquidation policy as the active policy variable. Not only pricetargeting but also the deterrence of runs is an objective of the central bank for attaining the socially optimal allocation.

A state-contingent money supply, however, does not impact the agent's spending behavior: the individual agents exclusively care for their individual real allocation at $t=1, y / n$, versus $t=2, R(1-y) /(1-n)$. These allocations are independent of nominal quantities $\left(M, P_{1}\right)$. That is, money is neutral. Given a realization of an individual real allocation $y / n$, the identity:

$$
\frac{y}{n}=\frac{M(n)}{P_{1}}
$$

pins down a relationship that needs to hold between the money supply and the price level that clears the market. The central bank can implement all money supplies and price level pairs $\left(M, P_{1}\right)$ that satisfy equation (27). And as soon as the price level goal $P_{1}$ is pinned down, contingent on the realization $\frac{y}{n}$, the money supply that solves equation (27) is unique. But in equation (27) the classic dichotomy holds, and the choice of the right-hand side $\left(M, P_{1}\right)$ cannot alter the left-hand side, i.e., cannot alter incentives to run. Consequently, if the central bank wants to impact consumers' behavior to run on the central bank to implement the social optimum, it can only do so by altering the real goods supply $y$ through adjustment of its liquidation policy.

In summary. Given the previous discussion, a state-contingent money supply strikes us 
as odd monetary policy. First, the usual inclination for central banks is to accommodate an increase in demand with a rise, rather than a decline in the money supply. A central bank that reacts to an increase in demand by making money scarce may undermine trust in the monetary system. In particular, and needless to say, a spending suspension might create considerable havoc; the experience in Argentina at the end of 2001 provides ample proof. Even if this was not the case, monetary neutrality implies that adjusting the money supply does not affect the run decisions of agents. Therefore, we think that this particular escape route from the CBDC trilemma needs to be treated with considerable caution.

\section{Voluntary participation in CBDC and competition by private banks}

The main model assumes that all consumers invest in a CBDC. It remains to clarify whether agents may be better off using the investment technology on their own, rather than relying on the central bank. This is an important question: if agents were to decide to stay in autarky and invest in the investment technology directly, they may have incentives to supply goods at the interim stage, thus, potentially undermining the central bank's liquidation policy. Similarly, if the outside option is not autarky but investing in deposits with a different, private bank, then the liquidation policy of that private bank has implications for the aggregate real goods supply at the interim stage, again impairing the effectiveness of the central bank's policy. We now discuss both.

\subsection{Autarky and voluntary participation in a CBDC}

Assume all but one agent invest in a CBDC. Assume that this single agent invests in the real technology at $t=0$, yielding storage between $t=0$ and $t=1$, and yielding $R>1$ when held between $\mathrm{t} t=0$ and $t=2$. Then, at $t=1$, she would learn her type. If she is impatient, she will liquidate the technology, yielding 1 unit of the real good, and she would consume her good. She would not sell the good against nominal CBDC deposits, since she

only cares about consumption at $t=1$. In the case where she is impatient, she is worse off in comparison to an agent who invested in CBDCs with the central bank if the central bank offers the socially optimal allocation and manages to implement a run-deterring policy. This 
is so, since under the latter, an individual impatient agent gets $x_{1}^{*}>1$ real goods.

If the individual agent is patient, she will stay invested in the technology until time two. There, the technology yields $R>1$ units of the good. The agent will, thus, be better off than under investment in a CBDC since $x_{2}^{*}<R$; see Section 3.1. But, in particular, also in the patient case, the individual agent will not offer goods for sale in the interim period, since liquidation and selling against a CBDC will only yield $x_{2}^{*}$ in $t=2$. Thus, in any case, patient

or impatient, the agent who invests in autarky will not have an incentive to undermine the central bank's policy by increasing the goods supply in the interim period.

Does the agent prefer to remain in autarky rather than participating in the CBDC? Exante, the risk-averse agent cannot know whether she will turn out to be patient or impatient. Diamond and Dybvig (1983) show that pooling of resources via banking can attain the social optimum under an absence of runs, while investment under autarky cannot. That is, the single agent is always better off investing in the CBDC account if the central bank offers optimal risk-sharing and implements a run-deterring policy. Thus, participation in the CBDC account is individually rational.

What if the central bank runs a policy of full price stability at goal $\bar{P}$ ? In that case, our second main result, Corollary 9, shows that runs on the central bank do not occur but $x_{1} \leq 1$. Thus, for all $x_{1}<1$, investing in a CBDC is dominated by investing in autarky. Voluntary participation thus requires $x_{1}=1$ or $M=\bar{P}$, implying $x_{2}=R$. The agent is then indifferent between investing in a CBDC and staying in autarky. Yet, if she stayed in autarky, she will not undermine the central bank's liquidation policy for the reasons above.

In the case of a partial price-stable policy, the situation is as in Diamond and Dybvig (1983). Ex-ante, the agent cannot know whether a run occurs or not. Conditional on the no-run equilibrium, we implement the social optimum and the agent is better off investing in a CBDC. But conditional on the run equilibrium, she was better off in autarky. From within the model, it is not possible to attach likelihoods for each equilibrium.

\subsection{Can private banks undermine the central bank's policy?}

The question of under what circumstances consumers prefer investing in a CBDC account with the central bank rather than investing in demand deposits with private banks, with implications for how both types of banks can coexist is addressed in Fernández-Villaverde 
et al. (2020). In this section, we will analyze the private banks' incentives to provide goods at the interim stage, conditional on the coexistence of private banks with the central bank.

Goods supply. If the central bank coexists with private banks, it controls the market of goods only partially, with the remainder of the real goods being supplied by commercial banks. As before, the measure of agents is normalized to one, divided between a share $\alpha \in(0,1)$ of agents who are CBDC customers at the central bank and a share $1-\alpha$ who are customers at private banks. Assume that all agents invest their 1 unit endowment in their corresponding bank and that the private banks invest in the same asset as the central bank does. Then, at $t=1$, the central bank can supply up to $\alpha$ goods via liquidation, while private banks can supply up to $1-\alpha$ goods.

Assume that there is one centralized goods market to which customers and banks have access. That is, CBDC depositors can spend CBDC balances on goods supplied by private banks and private bank customers can spend their private deposit balances on goods supplied by the central bank. Let $n$ denote the total measure of spending agents across both customer groups at the central bank and private banks, given by

$$
n=\alpha n_{C B}+(1-\alpha) n_{P},
$$

where $n_{C B}$ is the total share of consumers at the central bank who spend, while $n_{P}$ is the total share of consumers at the private bank who spend. Given total spending $n$ in period $t=1$, let $y_{P}(n)$ be the share of assets liquidated by private banks. In contrast, let $y_{C B}(n)$ be the central bank's liquidation policy, i.e., the share of assets liquidated by the central bank. The total goods supply $y$ in the centralized market at the interim stage is then:

$$
y(n)=\alpha y_{C B}(n)+(1-\alpha) y_{P}(n) .
$$

Private deposit making. To collect investment in $t=0$, the private banks offer a nominal demand-deposit account in return for 1 unit of the real good. The private nominal accounts are denominated in units of the CBDC. Due to competition with the central bank, the private contract also offers $M$ units of the CBDC in $t=1$ or $M(1+i(n))$ units in $t=2$.

To service withdrawals in terms of CBDC, private banks first observe their customers' CBDC withdrawal needs $n_{P}$, and borrow the required amount $(1-\alpha) n_{P} M$ of the CBDC from the central bank at the beginning of period $t=1$. The central bank creates the CBDC 
quantity $(1-\alpha) n_{P} M$ on demand for the private banks. Private banks observe CBDC spending at the central bank $n_{C B}$, yielding aggregate spending $n$. During period one, the private banks sell the share $y_{P}(n)$ of their real goods investment at price $P_{1}$ at the centralized market to all consumers, thus receiving proceeds of $P_{1} y_{P}(n)(1-\alpha)$ units of the CBDC in return, where $P_{1}$ satisfies market clearing:

$$
M\left((1-\alpha) n_{P}+\alpha n_{C B}\right)=P_{1}\left(y_{P}(n)(1-\alpha)+y_{C B}(n) \alpha\right)
$$

The private banks use these CBDC proceeds to (partially) repay their loan to the central bank at zero interest within period one. Since the central bank retains only partial control over the goods market, it generically no longer holds $n_{C B} M=P_{1} y_{C B}(n)$. As a consequence, the private banks can hold positive or negative CBDC balances $(1-\alpha)\left(P_{1} y_{P}(n)-n_{P} M\right)$ with the central bank between $t=1$ and $t=2$.

We seek to examine a range of possibilities for the private bank withdrawals $n_{P}$ as well as liquidation choices $y_{P}$. Thus, it is useful to impose the condition that private banks make zero profits, regardless of the "circumstances" $n_{P}$ or their choice for $y_{P}$. This requires some careful calculation, which we provide in Appendix 12, and only summarized here.

We assume that the central bank charges or pays the nominal interest rate $z=\left(R P_{2} / P_{1}\right)-$ 1 on the excess or deficit CBDC balances of private banks, to be settled at the end of $t=2$. Note that $z>i$, if $x_{1}>1$ and equals the internal nominal shadow interest rate regarding private bank liquidation choices. Moreover, we impose a market share tax at the end of period $t=2$ in order to compensate for profits or losses due to circumstances $n_{P}$.

At $t=2$, the remaining private customers spend the quantity $(1-\alpha)\left(1-n_{P}\right) M(1+i(n))$ of private CBDC accounts that the private banks borrow from the central bank at the beginning of $t=2$. The private banks sell their returns on the remaining investment $R\left(1-y_{P}(n)\right)(1-\alpha)$ at price $P_{2}$, where $P_{2}$ satisfies market clearing

$$
\begin{aligned}
& M(1+i(n))\left((1-\alpha)\left(1-n_{P}\right)+\alpha\left(1-n_{C B}\right)\right)= \\
& P_{2} R\left(\left(1-y_{P}(n)\right)(1-\alpha)+\left(1-y_{C B}(n)\right) \alpha\right) .
\end{aligned}
$$

At the end of $t=2$, the private banks settle their accounts with the central bank, taking into account the remaining balances at $t=1$ adjusted for interest, the end-of-period 
tax compensating for circumstances $n_{P}$, the loan at the beginning of $t=2$ and the sales proceeds at $t=2$.

Joint liquidation policies. The actions of private banks and the central bank may not be perfectly aligned when it comes to the liquidation of assets and the supply of goods at the interim stage. Private banks can have various objectives depending on their ownership structure and may be subject to regulation of their liquidation policy, both shaping $y_{P}$. Independently of whether private banks maximize depositor welfare as in Diamond and Dybvig (1983), or pursue some other objective, the prevention of runs is key. We have seen above that runs occur if the provision of real goods at the interim stage is high. Since the market is centralized, for the spending incentives of bank customers it is irrelevant whether these goods are provided by the central bank's or the private bank's liquidation of assets.

Hence, as before, a run-deterring liquidation policy $y(\cdot)$ is a function of aggregate spending $n$ such that the real allocation at $t=1$ undercuts the real allocation at $t=2$ :

$$
\frac{y(n)}{n}<R \frac{(1-y(n))}{1-n}, \quad \text { for all } n \in[\lambda, 1]
$$

Thus, again, a run-deterring policy satisfies

$$
y(n)<\frac{n R}{1+n(R-1)}, \quad \text { for all } n \in[\lambda, 1] .
$$

Perfect coordination. If the central bank and the private banks coordinate perfectly, i.e., act as one entity, and have full control over the asset liquidation, then all run-deterring policies are possible, as in the case where the central bank is a monopolist. But why would they coordinate perfectly? By the market's centralization, the destiny of the central bank is intertwined with the destiny of the private banks and both types of banks have an interest in deterring runs. In particular, the private bank will, therefore, not undermine a central bank's run-deterring policy by supplying additional goods when, for instance, prices are high, since this might cause a run not only on the central bank but also on the private bank. Coordination is therefore among the equilibrium outcomes.

Runs under imperfect coordination. For general liquidation policies $y_{P}$ of private banks, runs can occur, as the following example shows. Assume that the private bank for some reason follows a liquidation rule $y_{P}(n) \in[0,1]$ where $y_{P}\left(n_{b}\right)=1$ for all $n \geq n_{b}$ where 
$n_{b} \in(0,1)$. For instance, $n_{b}=1-\alpha$, i.e., the private bank is subject to regulation and has to liquidate all assets if a fraction of its customers equal to its market share spends. In that case, as we show next, the central bank's capacity to deter runs depends on the size of the private banking sector, i.e., its market power $\alpha$. Since the central bank can only control the liquidation of its own investment $y_{C P}$, via (32) and (29), a run-deterring policy $y_{C B}$ needs to satisfy

$$
y_{C B}(n)<\frac{R n-(1-\alpha) y_{P}(n)(R n+1-n)}{\alpha(R n+1-n)}, \quad \text { for all } n \in[\lambda, 1] .
$$

Now assume $n>n_{b}$, such that $y_{P}(n)=1$. If in addition the central bank has a small market share $\alpha \rightarrow 0$, then the numerator converges to $-(1-n)$, while the denominator goes to zero, $\alpha(1+(R-1) n) \rightarrow 0$. That is, for $n_{b}<n<1$, the right-hand side in (34) goes to minus infinity such that (34) cannot hold. This implies that the run equilibrium exists.

A sufficient condition: Run-deterrence under imperfect coordination. The example above makes clear that the central bank's share in the deposit market needs to be large enough in order to prevent runs. The following proposition provides the appropriate bound under which the central bank can ensure the absence of a run, regardless of the private bank's liquidation schedule $y_{P}:[\lambda, 1] \rightarrow[0,1]$.

Proposition 14. Suppose that the central bank's share in the deposit market satisfies

$$
\alpha>\frac{1-\lambda}{(1-\lambda+R \lambda)}
$$

Then the central bank can always find a run-deterring liquidation policy $y_{C B}:[\lambda, 1] \rightarrow[0,1]$, regardless of the private bank's liquidation policy $y_{P}:[\lambda, 1] \rightarrow[0,1]$.

Such an $\alpha \in(0,1)$ exists since $\frac{1-\lambda}{(1-\lambda+R \lambda)} \in(0,1)$. Thus, the right-hand side $\frac{1-\lambda}{(1-\lambda+R \lambda)}$ of equation (35) imposes a lower bound on the balance-sheet size of the central bank as a percentage of the total demand deposit market, such that run-deterring policies remain possible despite coexisting private banks that are subject to liquidation restrictions.

Proof. [Proposition 14] We need to show that for any private bank liquidation policy $y_{P}$ : $[\lambda, 1] \rightarrow[0,1]$, there is a central bank liquidation policy $y_{C B}:[\lambda, 1] \rightarrow[0,1]$ so that (34) is satisfied. To derive a sufficient condition on the central bank's market share $\alpha$ under which 
it can nevertheless implement a run-deterring policy, note that by $R>1$, the right-hand side in (34) declines in the value $y_{p}$ for all $\alpha \in(0,1)$. Thus, if a central bank policy $y_{C P}$ is run-deterring for $y_{P}=1$ for all $n \in[0,1]$, then $y_{C P}$ is also run-deterring for a private bank policy $y_{P}(n) \leq 1$ for all $n \in[0,1]$. Thus, assume $y_{P}=1$ for all $n \in[0,1]$. Then, a sufficient condition for a run-deterring policy against all private bank policies $y_{P}$ is:

$$
y_{C B}(n)<\frac{R n-(1-\alpha)(R n+(1-n))}{\alpha(1+(R-1) n)}=1-\frac{1-n}{\alpha(1+(R-1) n)}, \quad \text { for all } n \in[\lambda, 1] \text {. }
$$

The right-hand side is increasing in $n$ and $y_{C B}(n)$ cannot undercut zero. Thus, an $\mathrm{n} \alpha$ such that:

$$
0<1-\frac{1-\lambda}{\alpha(1+(R-1) \lambda)}
$$

is a sufficient condition for the existence of a policy $y_{C B} \in[0,1]$ that satisfies $(36)$.

\section{$9 \quad$ Extensions}

\subsection{Token-based CBDC}

With a token-based CBDC, a central bank issues anonymous electronic tokens to agents in period 1, rather than accounts. ${ }^{7}$ These electronic tokens are more akin to traditional banknotes than to deposit accounts. Trading with tokens only requires trust in the authenticity of the token rather than knowledge of the identity of the token holder. Thus, token-based transactions can be made without the knowlegde of the central bank.

Technically, and with appropriate software, digital tokens can be designed in such a way that each unit of a token in $t=1$ turns into a quantity $1+i$ of tokens in $t=2$, with $i$ to be determined by the central bank at the beginning of period $t=2$ : even a negative nominal interest rate is possible. ${ }^{8}$

\footnotetext{
${ }^{7}$ This can be done with or without a blockchain. In the second case, a centralized ledger to record transactions can be kept by a third-party that is separate from the central bank. That third party could also potentially pay interest or impose a suspension of spending. For the purpose of this paper, we do not need to worry about the operational details of such a third party or to specify which walls should exist between it and the central bank to guarantee the anonymity of tokens.

${ }^{8}$ Historically, we have examples of banknotes bearing positive interest (for instance, during the U.S. Civil War, the U.S. Treasury issued notes with coupons that could be clipped at regular intervals) and negative
} 
With that, the analysis in the previous sections still holds, since nothing of essence depends on the identity of the spending agents other than total CBDC tokens spent in the goods market. With a token-based CBDC, agents obtain $M$ tokens in period $t=0$, and decide how much to spend in periods $t=1$ and $t=2$. Thus, the same allocations can be implemented except for those that require the suspension of spending, as discussed in Subsection 7 .

For the latter, the degree of implementability depends on technical details outside the scope of this paper. Note that even with a token-based system, the transfer of tokens usually needs to be registered somewhere, e.g., on a blockchain. It is technically feasible to limit the total quantity of tokens that can be transferred on-chain in any given period. A pro-rata arrangement can be imposed by taking all the pending transactions waiting to be encoded in the blockchain, taking the sum of all the spending requests, and accordingly dividing each token into a portion that can be transferred and a portion that cannot. It may be that off-chain solutions arise circumventing some of these measures, but their availability depends on the precise technical protocol of the CBDC token-based system. In the case where the token-based CBDC is operated by a centralized third party, such an implementation is even easier.

\subsection{Synthetic CBDC and retail banking}

With a synthetic CBDC, agents do not hold the central bank's digital money directly. Rather, agents hold accounts at their own retail bank, which in turn holds a CBDC not much different from current central bank reserves. This may be due to tight regulation by the monetary authority. The retail banks undertake the real investments envisioned for the central bank in our analysis above. A synthetic CBDC, therefore, corresponds to the model sketched in Section 8.2 with $\alpha=0$.

The key difference from the current cash-and-deposit-banking system is that cash does not exist as a separate central bank currency or means of payment. That is, in a synthetic CBDC system, agents can transfer amounts from one account to another, but these transactions are always observable to the banking system and, thereby, the central bank. Likewise, agents (and banks) cannot circumvent negative nominal interest, while they could do so in a classic

interest (demurrage-charged currency, such as the prosperity certificates in Alberta, Canada, during 1936). Thus, an interest-bearing electronic token is only novel in its incarnation, but not in its essence. 
cash-and-deposit banking system by withdrawing cash and storing it.

For the purpose of our analysis, observability is key. Our analysis is relevant in the case of a systemic bank run, i.e., if the economy-wide fraction of spending agents exceeds the equilibrium outcome. Much then depends on the interplay between the central bank and the system of private banks. For example, if the liquidation of long-term real projects is up to the retail banks, and these retail banks decide to make the same quantity of real goods available in each period, regardless of the nominal spending requests by their depositors, then the aggregate price level will have to adjust. The central bank may seek to prevent this either by imposing a suspension of spending at retail banks or by forcing banks into higher liquidation of real projects: both would require considerable authority for the central bank. Proposition 14, for instance, says that with $\alpha=0$, the central bank alone cannot implement a run-deterring policy when offering a synthetic CBDC. Run deterrence then requires retail banks to control liquidation in a particular way.

\subsection{Cash}

The key difference to a fully cash-based system is that spending decisions can only be observed in the goods market, rather than by also tracing accounts or transactions on the blockchain. In principle, the payment of nominal interest rates on cash is feasible, but is demanding in practice. Excluding nominal interest rates on cash, due to these practical considerations, implies the cash-and-deposit banking system discussed in Section 9.2 and the restrictions discussed there. The tools available to a central bank are now considerably more limited. These limitations may be a good thing, as they may impose a commitment technology and may thus lead to the prevention of an equilibrium systemic bank run in the first place, but the restricted tool set may be viewed as a burden ex-post, should such a bank run occur.

\section{Conclusion}

Diamond and Dybvig (1983) have taught us that the implementation of the social optimum via the financial intermediation of banks comes at the cost of making these banks prone to runs. We have argued that this dilemma becomes a trilemma when the central bank acts as 
the intermediary offering a CBDC because central banks are additionally concerned about price stability. As summarized in Figure 1, a central bank that wishes to simultaneously achieve a socially efficient solution, price stability, and financial stability (i.e., absence of runs) will see its desires frustrated. We have shown that a central bank can only realize two of these three goals at a time.

In its role as the intermediary, the central bank collects and invests the real goods endowments of the agents in a real production technology, offering a nominal CBDC contract in return. At an interim period, the agents learn whether they enjoy late (patient agent) or early (impatient agent) consumption and, then, make their nominal spending decisions. A central bank run occurs if patient agents also decide to spend their CBDC balances early. Patient agents do spend early when the real value from early spending exceeds the real value from late spending. But real values depend on the central bank's liquidation policy of real investment. The central bank observes aggregate nominal spending and then decides how much of its real investment to liquidate in order to supply goods to the agents spending their balances. The price level for real goods then adjusts such that nominal CBDC spending clears the real goods market. In contrast, a private intermediary would need to take the price level as given such that the price level jointly with aggregate nominal spending pins down the necessary liquidation of its real investment.

As our main result, we have demonstrated that the central bank can always implement the socially optimal allocation in dominant strategies and deter central bank runs at the price of threatening inflation off-equilibrium. If price-stability objectives for the central bank imply that the central bank would not follow through with that threat, then allocations either have to be suboptimal or prone to runs.

We hope to extend our analysis in several important directions. For instance, we can have a richer "real" side of the economy, including analyzing how a CBDC can affect heterogeneous agents. We can also study how a CBDC will affect a wider range of financial assets beyond demand deposits. These are vital considerations to judge the desirability of moving toward a CBDC world. 


\section{Appendix A: Proofs}

Proof. [Proposition 8] Proof (i): Via the market clearing condition (7), setting $P_{1}(n) \equiv \bar{P}$ for all $n$ requires $y(n)=\frac{M}{\bar{P}} n$, for all $n \in[0,1]$. Thus, via $(11), x_{1}(n)=y(n) / n=\frac{M}{\bar{P}}$ is constant for all $n$. Last, since the central bank cannot liquidate more than the entire investment in the real technology, $y(n) \in[0,1]$ for all $n$, together with $x_{1}$ constant requires, in particular, $\frac{M}{\bar{P}}=x_{1}=x_{1}(1)=y(1) \leq 1$. Thus, $M \leq \bar{P}$. Proof (ii): When additionally requiring price stability, $P_{1}(n)=P_{2}(n) \equiv \bar{P}$, the market clearing condition (8) together with (18) yields (20).

Proof. [Corollary 9] Proof (i): We know that price stability demands $x_{1} \leq 1$ but the social optimum satisfies $x_{1}^{*}>1$. Proof (ii): $\bar{x}_{1} \leq 1$ implies $x_{2}(n)=\frac{1-y(n)}{1-n} R=\frac{1-n \bar{x}_{1}}{1-n} R \geq R>1 \geq \bar{x}$. Since the real value of the allocation at $t=2$ always exceeds the real value of the time one allocation at $t=1$, patient agents never spend at $t=1$; thus, there are no runs. Proof (iii): By equation (19), $\frac{\bar{P}}{M} \geq 1$, implies $i(n)=\frac{\frac{\bar{M}}{M}-n}{1-n} R-1 \geq R-1>0$ for all $n \in[\lambda, 1]$ by $R>1$. Further, $\frac{\bar{P}}{M} \geq 1$ implies that $i(n)$ increases in $n$.

Proof. [Proposition 12] Proof (i): Equation (21) follows immediately from (7) and the constraint $y(n) \leq 1$. Proof (ii): In $n=n_{c}$, we have $\frac{M}{P} n=1$. Therefore, $n_{c}>0$. By assumption $\bar{P}<M$, thus $n_{c}<1$, with $n_{c} \in(0,1)$. Equation (21) implies that $x_{1}(n)=y(n) / n$ is constant at the level $\bar{x}=M / \bar{P}$, as long as $y(n)<1$ : this is the case for $n<n_{c}$. For $n \geq n_{c}, y(n) \equiv 1$. All goods are liquidated, so $x_{1}(n)=1 / n$. Equation $P_{1}(n)=M n$ follows from equation (7). Proof (iii): Equation (22) follows from (8) combined with (21). Proof (iv): This is straightforward, when plugging in $(21)$ into $P_{2}(n)$ and observing that $n_{0}$ is positive only for $R>M / \bar{P}$.

\section{Appendix B: Private bank accounting}

Consider the collective of private banks with market share $(1-\alpha) \in(0,1)$. For the sake of brevity, we refer to the collective as "the private bank." A fraction $n_{P}$ of the private bank's customers spend in $t=1$, while a fraction $n_{C B}$ of the central bank's customers do so, for a total fraction $n$ of all agents $n=(1-\alpha) n_{P}+\alpha n_{C B}$. Agents are promised $M$ units of the CBDC, when spending in $t=1$, or $M(1+i)$ units, when spending in $t=2$. The central 
bank liquidates $y_{C B}$ goods in period $t=1$, while the private bank liquidates $y_{P}$, for total liquidation $y=(1-\alpha) y_{P}+\alpha y_{C B}$. For accounting, we introduce some notation. The private bank borrows CBDC $L_{1}$ from the central bank to meet withdrawals at the beginning of each period, repaying the loan at the end of the period with the sales proceeds $S_{1}$ from selling real goods. No interest is charged for the within-period loan.

The difference $D_{1}$ at the end of period $t=1$ is kept on account at the central bank, earning or paying the nominal interest rate $z$, to be settled at the end of period $t=2$. Further, the bank has to pay a tax $\tau(1-\alpha)$ denoted in CBDC at the end of period 2 (or receive this as a subsidy, if $\tau<0$ ). The interest rate $z$ and the $\operatorname{tax} \tau$ are chosen by the central bank (CB in the accounting below), and may depend on $n_{P}$ and choices $y_{P}$ of the private bank. We seek to calculate $x$ and $\tau$ so that the private bank makes zero profits, i.e., is left with zero CBDC balances $D_{2}$ at the end of period 2, after having liquidated and sold all its remaining goods at the end of period 2. Accounting requires

Accounting in period $t=1$ :

$$
\begin{aligned}
\text { Loan from CB: } & L_{1}=(1-\alpha) n_{P} M \\
\text { Sales proceeds: } & S_{1}=(1-\alpha) P_{1} y_{P} \\
\text { Difference: } & D_{1}=S_{1}-L_{1}=(1-\alpha)\left(P_{1} y_{P}-n_{P} M\right)
\end{aligned}
$$

Accounting in period $t=2$ :

$$
\begin{array}{rll}
\text { Loan from CB: } \quad L_{2} & =(1-\alpha)\left(1-n_{P}\right)(1+i) M \\
\text { Sales proceeds: } \quad S_{2} & =(1-\alpha) P_{2} R\left(1-y_{P}\right) \\
\text { CB account: } \quad A_{2} & =(1+z) D_{1}-\tau(1-\alpha) \\
\text { Difference: } \quad D_{2} & =A_{2}+S_{2}-L_{2} \\
& =(1-\alpha)\left(P_{2} R+\left((1+z) P_{1}-P_{2} R\right) y_{P}-(1+i) M-(z-i) n_{P} M-\tau\right)
\end{array}
$$

\section{Market clearing:}

$$
\begin{array}{lcl}
\text { In } t=1: & P_{1} y & =n M \\
\text { In } t=2: & P_{2} R(1-y) & =(1-n)(1+i) M
\end{array}
$$


Sum $(1+i)$ times the market clearing equation for $P_{1}$ with the equation for $P_{2}$ to obtain $P_{2} R+\left((1+i) P_{1}-P_{2} R\right) y=(1+i) M$. Use the latter equation to replace $(1+i) M$ in the last expression for $D_{2}$ to find

$$
\frac{D_{2}}{P_{1}(1-\alpha)}=(i-s)\left(y_{P}-y\right)+(z-i)\left(y_{P}-n_{P} x_{1}\right)-\frac{\tau}{P_{1}}
$$

where, as usual, $x_{1}=\frac{M}{P_{1}}$ is the amount of real goods acquired by agents in period $t=1$ and where we introduce:

$$
s=\frac{P_{2}}{P_{1}} R-1
$$

to denote the "shadow" nominal interest rate for private banks, equating liquidating a unit of the good in $t=1$, selling at $P_{1}$ and investing at the shadow nominal return $1+s$ to keeping the unit of good and thus selling $R$ units at price $P_{2}$. Notice that $y=n x_{1}$ and the market clearing equations imply

$$
1+s=(1+i) \frac{1-n}{1-x_{1} n} x_{1}
$$

and, thus, $s>i$, whenever $x_{1}>1$. In particular, this is the case at the efficient outcome. We note that $s=i$, if and only if $x_{1}=1$, which is the maximal full price-stable solution as well as the market allocation, when agents engage in self-storage.

Suppose now that the private bank sells exactly as many goods as purchased by their withdrawing customers, i.e., $y_{P}=n_{P} x_{1}$. Absent $\tau$, equation (38) reveals that the private bank will make a loss or profit, if $x_{1} \neq 1$ and if $y_{P} \neq y$, i.e., $n_{P} \neq n$. For example, if the share of private-bank customers who go shopping in $t=1$ is larger than the average share of customers who shops economy-wide, $n_{P}>n$, and if the allocation achieves $x_{1}>1$ and thus $s>i$, then the private bank incurs a loss $D_{2}<0$, absent $\tau$, as the opportunity costs for servicing agents in $t=1$ are high. We shall use these observations to fix the $\operatorname{tax} \tau$ to compensate for these losses or profits, and assume that

$$
\tau=P_{1}(i-s)\left(n_{P}-n\right) x_{1}
$$

from here onward. This $\tau$ depends on the specifics of the bank only via the "circumstances" $n_{P}$ and does not depend on the choice $y_{P}$. To take care of the case where $y_{P} \neq n_{P} x_{1}$, we use the central bank-account interest rate $z$. Solving for $z$ per setting $D_{2}=0$ in (38) and 
imposing (41) yields the following result, which we formulate as a proposition.

Proposition 15. Suppose $\tau$ satisfies (41). Then

$$
\left\{D_{2}=0\right\} \Leftrightarrow\left(\left\{y_{P}=n_{P} x_{1}\right\} \text { or }\{z=s\}\right)
$$

In sum, taxing the "circumstance" profits per (41) and paying an internal interest rate $z$ on central bank balances equal to the shadow nominal interest rate $s$ achieves the objective that private banks make zero profits, regardless of their circumstances $n_{P}$ and regardless of their liquidation choice $y_{P}$.

Lemma 16. If the private bank sets $y_{P} \equiv y_{C B}$, then the interest rate for which the private bank's balances with the central bank are zero equals $z=i$ and $\tau=0$.

That is, if the private bank liquidates the same share of assets as does the central bank, then the interest rate on CBDC balances $z=i$ sets bank profits to zero.

Proof. [Lemma 16] With $\tau=0$, the CBDC balance at the end of $t=2$ equals

$$
\begin{aligned}
D_{2} & =(1-\alpha)\left(P_{2} R\left(1-y_{p}\right)-\left(1-n_{p}\right)(1+i) M+(1+z)\left(P_{1} y_{p}-n_{p} M\right)\right) \\
& =(1-\alpha) M *\left(\begin{array}{c}
(1+i)\left(\frac{\left(1-y_{p}\right)(1-n)}{1-y}-\left(1-n_{p}\right)\right) \\
+(1+z)\left(\frac{n y_{p}}{y}-n_{p}\right)
\end{array}\right)
\end{aligned}
$$

where, at the last equality, we have plugged in $P_{1}$ and $P_{2}$. Then,

$$
\frac{\left(1-y_{p}\right)(1-n)}{1-y}-\left(1-n_{p}\right)=-\left(\frac{n y_{p}}{y}-n_{p}\right)
$$

if and only if

$$
\frac{y\left(1-y_{p}\right)-n\left(y-y_{p}\right)}{y(1-y)}=1
$$

For $\alpha \in(0,1), y_{P} \equiv y_{C B}$ implies $y_{p}=y$. If $y=y_{p}$, then equations (45) and (44) are true. Thus, for $y=y_{p}$ the choice $z=i$ puts $D_{2}=0$. 


\section{References}

Allen, F., E. Carletti, And D. Gale (2014): "Money, Financial Stability and Efficiency," Journal of Economic Theory, 149, 100-127.

Allen, F. And D. Gale (1998): "Optimal Financial Crises," Journal of Finance, 53, $1245-1284$.

Amoussou-Guenou, Y., B. Biais, M. Potop-Butucaru, and S. TucciPiergiovanni (2019): "Rationals vs. Byzantines in consensus-based blockchains," arXiv preprint arXiv:1902.07895.

Andolfatto, D., A. Berentsen, And F. M. Martin (2020): "Money, Banking, and Financial Markets," Review of Economic Studies, 87, 2049-2086.

Auer, R. And R. BÖHme (2020): "The Technology of Retail Central Bank Digital Currency," BIS Quarterly Review, March, pp 85-100, March, 85-100.

Auer, R., G. Cornelli, J. Frost, Et Al. (2020): "Rise of the central bank digital currencies: drivers, approaches and technologies," Tech. rep., Bank for International Settlements.

BAgehot, W. (1873): Lombard Street: A Description of the Money Market, Scribner, Armstong \& Co.

Barrdear, J. And M. Kumhof (2016): "The Macroeconomics of Central Bank Issued Digital Currencies," Bank of England Working Paper 605, Bank of England.

BeCh, M. L. And R. GaRRATt (2017): "Central bank cryptocurrencies," BIS Quarterly Review September.

Benigno, P. (2019): "Monetary Policy in a World of Cryptocurrencies," CEPR discussion paper no. DP13517, CEPR.

Benigno, P., L. M. Schilling, And H. Uhlig (2019): "Cryptocurrencies, Currency Competition, and the Impossible Trinity," Working Paper 26214, National Bureau of Economic Research. 
Berentsen, A. (1998): "Monetary Policy Implications of Digital Money," Kyklos, 51, 89117.

Biais, B., C. Bisiere, M. Bouvard, and C. Casamatta (2019a): "The blockchain folk theorem," The Review of Financial Studies, 32, 1662-1715.

Biais, B., C. Bisière, M. Bouvard, and C. Casamatta (2019b): "Blockchains, Coordination, and Forks," in AEA Papers and Proceedings, vol. 109, 88-92.

Bordo, M. D. And A. T. Levin (2017): "Central Bank Digital Currency and the Future of Monetary Policy," Working Paper 23711, National Bureau of Economic Research.

Böser, F. And H. Gersbach (2019a): "A Central Bank Digital Currency in Our Monetary System?" Mimeo, Center of Economic Research at ETH Zurich.

_ (2019b): "Do CBDCs Make a Difference?" Working paper.

Brunnermeier, M. K. And D. Niepelt (2019): "On the Equivalence of Private and Public Money," Journal of Monetary Economics, 106, 27-41.

Chapman, J., R. Garratt, S. Hendry, A. McCormack, and W. Mcmahon (2017): "Project Jasper: Are distributed wholesale payment systems feasible yet?" Financial System, 59 .

Chiu, J., M. Davoodalhosseini, J. Hua Jiang, and Y. Zhu (2019): "Bank Market Power and Central Bank Digital Currency: Theory and Quantitative Assessment," Bank of Canada Staff Working Paper.

Choi, M. and G. Rocheteau (2020): "Money mining and price dynamics," American Economic Journal: Macroeconomics.

Cong, L. W., Y. LI, AND N. WANG (2020): "Tokenomics: dynamic adoption and valuation," Working Paper 27222, National Bureau of Economic Research.

Davoodalhosseini, M., F. Rivadeneyra, and Y. Zhu (2020): "CBDC and Monetary Policy," Staff Analytical Notes 2020-4, Bank of Canada. 
Diamond, D. W. And P. H. Dybvig (1983): "Bank Runs, Deposit Insurance, and Liquidity," Journal of Political Economy, 91, 401-419.

Ebrahimi, Z., B. Routledge, and A. Zetlin-Jones (2019): "Getting Blockchain Incentives Right," Tech. rep., Carnegie Mellon University Working Paper.

EgGertsson, G. B. And M. Woodford (2003): "The Zero Bound on Interest Rates and Optimal Monetary Policy," Brookings Papers on Economic Activity, 1, 139-233.

FernándeZ-Villaverde, J. And D. SAnches (2019): "Can currency competition work?" Journal of Monetary Economics, 106, 1-15.

Fernández-Villaverde, J., D. Sanches, L. Schilling, and H. Uhlig (2020): "Central Bank Digital Currency: Central Banking For All?" Working Paper 26753, National Bureau of Economic Research.

Ferrari, M. M., A. Mehl, And L. Stracca (2020): "Central bank digital currency in an open economy," Discussion Paper 15335, CEPR.

Garratt, R. and M. R. van Oordt (2019): "Why Fixed Costs Matter for Proof-of-Work Based Cryptocurrencies," Available at SSRN.

Group of 30, T. (2020): "Digital Currencies and Stablecoins: Risks, Opportunities, and Challenges Ahead," Tech. rep., G30.

Huberman, G., J. Leshno, and C. C. Moallemi (2017): "Monopoly without a monopolist: An economic analysis of the bitcoin payment system," Bank of Finland Research Discussion Paper.

InGves, S. (2018): "Do We Need an E-krona?" Swedish House of Finance.

Kahn, C. M., F. Rivadeneyra, and T.-N. Wong (2019): "Should the central bank issue e-money?" Money, 01-18.

Keister, T. And D. R. Sanches (2019): "Should Central Banks Issue Digital Currency?" Working Paper 19-26, Federal Reserve Bank of Philadelphia. 
Krugman, P. R. (1998): "It's Baaack: Japan's Slump and the Return of the Liquidity Trap," Brookings Papers on Economic Activity, 29, 137-206.

Kydland, F. E. And E. C. Prescott (1977): "Rules Rather Than Discretion: The Inconsistency of Optimal Plans," Journal of Political Economy, 85, 473-491.

Lagarde, C. (2018): "Winds of Change: The Case for New Digital Currency," Singapore Fintech Festival.

Lagos, R. And R. Wright (2005): "A unified framework for monetary theory and policy analysis," Journal of Political Economy, 113, 463-484.

Leiva, D. R. And H. R. MendizÁBAl (2019): "Self-fulfilling runs and endogenous liquidity creation," Journal of Financial Stability, 45, 1-15.

Leshno, J. D. And P. Strack (2020): "Bitcoin: An Axiomatic Approach and an Impossibility Theorem," American Economic Review: Insights, 2, 269-86.

Li, J. AND W. MANn (2020): "Digital tokens and platform building," Unpublished working paper.

Lucas, R. E. And N. L. Stokey (1987): "Money and Interest in a Cash-in-Advance Economy," Econometrica, 55, 491-513.

Prat, J., V. Danos, And S. Marcassa (2019): "Fundamental pricing of utility tokens," THEMA Working Papers 2019-11, THEMA.

Prat, J. And B. Walter (2018): "An equilibrium model of the market for bitcoin mining," CESifo Working Paper Series 6865, CESifo.

SAleh, F. (2020): "Blockchain without waste: Proof-of-stake," Available at SSRN 3183935.

Schilling, L. And H. Uhlig (2019): "Some simple bitcoin economics," Journal of Monetary Economics, 106, 16-26.

Skeit, D. R. (2008): "Banking with Nominal Deposits and Inside Money," Journal of Financial Intermediation, 17, 562-584. 
_ (2019): "Digital Currency Runs," Draft, Warwick Business School.

Svensson, L. E. O. (1985): "Money and Asset Prices in a Cash-in-Advance Economy," Journal of Political Economy, 93, 919-944.

Woodford, M. (2003): Interest and Prices: Foundations of a Theory of Monetary Policy, Princeton University Press. 